\title{
Mediterranean ocean colour Level 3 operational multi-sensor processing
}

\author{
Gianluca Volpe ${ }^{1}$, Simone Colella ${ }^{1}$, Vittorio E. Brando ${ }^{1}$, Vega Forneris ${ }^{1}$, Flavio La Padula ${ }^{1}$, Annalisa Di Cicco ${ }^{1}$, \\ Michela Sammartino $^{1}$, Marco Bracaglia ${ }^{1,2}$, Florinda Artuso ${ }^{3}$, and Rosalia Santoleri ${ }^{1}$ \\ ${ }^{1}$ Istituto di Scienze Marine, Via Fosso del Cavaliere 100, 00133, Rome, Italy \\ ${ }^{2}$ Università degli Studi di Napoli Parthenope, Via Amm. F. Acton 38, 80133, Naples, Italy \\ ${ }^{3}$ Agenzia nazionale per le nuove tecnologie, l'energia e lo sviluppo economico sostenibile, Dipartimento Ambiente, \\ Centro Ricerche Frascati, Frascati, Italy
}

Correspondence: Gianluca Volpe (gianluca.volpe@cnr.it)

Received: 28 June 2018 - Discussion started: 11 July 2018

Revised: 9 January 2019 - Accepted: 20 January 2019 - Published: 12 February 2019

\begin{abstract}
The Mediterranean near-real-time multi-sensor processing chain has been set up and is operational in the framework of the Copernicus Marine Environment Monitoring Service (CMEMS). This work describes the main steps operationally performed to enable single ocean colour sensors to enter the multi-sensor processing applied to the Mediterranean Sea by the Ocean Colour Thematic Assembly Centre within CMEMS. Here, the multi-sensor chain takes care of reducing the inter-sensor bias before data from different sensors are merged together. A basin-scale in situ biooptical dataset is used both to fine tune the algorithms for the retrieval of phytoplankton chlorophyll and the attenuation coefficient of light, $\mathrm{Kd}$, and to assess the uncertainty associated with them. The satellite multi-sensor remote sensing reflectance spectra agree better with the in situ observations than those of the single sensors. Here, we demonstrate that the operational multi-sensor processing chain compares sufficiently well with the historical in situ datasets to also confidently be used for reprocessing the full data time series.
\end{abstract}

\section{Introduction}

The Copernicus Marine Environment Monitoring Service (CMEMS) is one of the six services of the Copernicus programme. It provides regular and systematic reference information on the physical state, variability, and dynamics of the ocean, ice, and marine ecosystems for the global ocean and the European seas. CMEMS delivers both satellite and in situ high-level products prepared by Thematic Assembly Centres (TACs) and modelling and data assimilation products prepared by Monitoring and Forecasting Centres (MFCs). The Ocean Colour Thematic Assembly Centre (OCTAC) builds and operates the European ocean colour operational service within CMEMS providing global, pan-European, and regional (Arctic Ocean, Atlantic Ocean, Baltic Sea, Black Sea, and Mediterranean Sea) ocean colour (OC) products based on Earth observation from OC missions (Le Traon, 2015; von Schuckmann et al., 2016, 2018). The OCTAC bridges the gap between space agencies, by providing ocean colour data, and users who need the added-value information not available from space agencies. Presently, the OCTAC relies on current and legacy OC sensors: MERIS (MEdium Resolution Imaging Spectrometer) from ESA, SeaWiFS (Seaviewing Wide Field-of-view Sensor) and MODIS (Moderate Resolution Imaging Spectroradiometer) from NASA, VIIRS (Visible Infrared Imager Radiometer Suite) from NOAA, and most recently the Copernicus Sentinel 3A OLCI (Ocean and Land Colour Instrument).

Starting from the Level 2 (L2) data downloaded from space agencies, the OCTAC generates Level 3 (L3) and Level 4 (L4) products in near-real-time (NRT) and delayed-time (DT) modes. Within CMEMS, L3 products refer to the single snapshot, or daily combined products, mapped onto a regular grid, while L4 are products for which a temporal averaging method and/or an interpolation procedure is applied to fill in missing data values. The NRT products are operationally produced daily to provide the best estimate of the 
ocean colour variables at the time of processing. These products are generated soon after the satellite swaths are available together with climatological ancillary data, e.g. meteorological and ozone data for atmospheric correction, and predicted attitude and ephemerides for data geolocation. In the DT processing, the updated ancillary data made available from the space agencies are used to improve the quality of the NRT data. NRT and DT data streams are hence designed to fulfil the operational oceanography-specific requirements for the near-real-time availability of high-quality satellite data with a sufficiently dense space and time sampling (e.g. Le Traon et al., 2015). Generally, once a year, the full data time series undergoes a reprocessing (REP) to ensure that the most recent findings are consistently applied and back-propagated to all data. REP products are multi-year time series produced with a consolidated and consistent input dataset and processing software configuration, resulting in a dataset suitable for long-term analyses and climate studies (von Schuckmann et al., 2017; Sathyendranath et al., 2017, and references therein).

Within CMEMS, observations from multiple missions are processed together to ensure homogenized and intercalibrated datasets for all essential ocean variables. Combining the observations from different platforms results in higher coverage compared with that of the single sensors. Moreover, the multi-sensor product allows non-expert users to access a robust and less ambiguous source of information. Currently in the OCTAC, the NRT and DT multi-sensor L3 and L4 products are derived from MODIS Aqua and NPPVIIRS data, while REP includes observations from SeaWiFS, MODIS Aqua, MERIS, and NPP-VIIRS. Global REP products are derived from two datasets: the OC-CCI (Climate Change Initiative; http://www.esa-oceancolour-cci.org/, last access: 7 February 2019) funded by the European Space Agency and the Copernicus GlobColour initially developed by the GlobColour project (http://www.globcolour.info/, last access: 7 February 2019) and then updated and produced in the framework of CMEMS. OLCI is foreseen to be included into the NRT-DT multi-sensor products in 2019 and in the REP when the quality of the data is deemed suitable.

In general, DT and REP products are meant to answer different questions and to satisfy different needs such as assimilation into operational models and climate studies, respectively. As such, DT data are expected to be as accurate as timeliness allows. The accuracy of REP data needs to be stable in time as these data, which are consistently processed with a single software version, are used for studying longtimescale phenomena. For the sake of timeliness, the accuracy of the NRT-DT data is relaxed with respect to the one associated with REP time series. In this respect, one of the aims of this work is to propagate the REP configuration to the DT processing mode, allowing for full compatibility between the two datasets and extending climate-fit research to the most recent observations.
Regional products differ from their global counterparts as they are specifically derived to accurately reflect the biooptical characteristics of each basin (e.g. Szeto et al., 2011; Volpe et al., 2007; Pitarch et al., 2016; D'Alimonte and Zibordi, 2003). Due to peculiarities in the optical properties, the Mediterranean Sea oligotrophic waters are less blue (30\%) and greener (15\%) than the global ocean (Volpe et al., 2007), causing an overestimation of the phytoplankton chlorophyll concentration $(\mathrm{Chl})$ retrievals by standard global algorithms (e.g. Bricaud et al., 2002; D'Ortenzio et al., 2002). In the last decade, more accurate regional bio-optical algorithms (e.g. MedOC4) were implemented in the single-sensor operational processing chains for the Mediterranean Sea (Santoleri et al., 2008; Volpe et al., 2012).

The main objective of this work is to provide Copernicus users with a comprehensive description of the method currently applied by GOS (the group for Global Ocean Satellite monitoring and marine ecosystem study of the Italian National Research Council, CNR) in the OCTAC context of CMEMS to produce the L3 multi-sensor ocean colour product over the Mediterranean Sea. The next section (Data and methods) describes the bio-optical dataset forming the basis for the development and validation of the regional algorithms for the Mediterranean Sea, an update of the MedOC4 parameterization, and the satellite data input and output of the operational processing chain. Section 3 gives an overview of the validation results obtained in the comparison between the multi-sensor satellite products and the in situ data.

\section{Data and methods}

\subsection{The Mediterranean Sea in situ bio-optical dataset: MedBiOp}

The development of geophysical products that best reproduce Mediterranean biogeochemical conditions relies on an in situ bio-optical dataset collected across the basin over 20 years (Fig. 1). Several parameters are routinely measured both for general oceanographic purposes (e.g. water temperature, salinity, oxygen content, fluorescence, and light attenuation) and for the calibration and validation of remote sensing data. These include phytoplankton pigment concentration via HPLC analysis (high-performance liquid chromatography), light absorption due to coloured dissolved organic matter (CDOM), light absorption due to algal and non-algal particles as well as to total suspended matter (TSM), particulate backscattering and apparent optical properties such as remote sensing reflectance (Rrs), and the diffuse attenuation coefficient $(\mathrm{Kd})$. In this work, the in situ Rrs dataset is used as input to update the MedOC4 $\mathrm{Chl}$ algorithm and to validate the multi-sensor satellite-derived Rrs product. The in situ Chl dataset is larger than the Rrs and all samples in correspondence to optical measurements are used to update the MedOC4 $\mathrm{Chl}$ algorithm, while all others are used to val- 
idate the multi-sensor satellite-derived $\mathrm{Chl}$ product. On the other hand, Kd measurements are only used to fine tune the Mediterranean algorithm for ocean colour retrieval.

In the OC processing chain the primary parameters used to derive the geophysical products are the spectral Rrs values. The most important objective of using the in situ radiometric measurements is to derive surface, above-water Rrs spectra from in-water profiles. The multispectral Satlantic profiling system (OCR-507) is made for measuring the upwelling radiance, $\operatorname{Lu}(z, \lambda)$, as well as the downward and upward irradiance, $\operatorname{Ed}(z, \lambda)$ and $\operatorname{Eu}(z, \lambda)$, and includes a reference sensor for the downward irradiance, $\operatorname{Es}(0, \lambda)$, mounted on the uppermost deck of the ship. Table 1 shows that the in situ and satellite sensor acquisition bands do not always match. Hence, to allow for a satellite-in situ data matchup, the in situ data spectral resolution is increased with the technique of band shifting (see Sect. 2.2.1). A Sea-Bird CTD and a tilt sensor are also part of the system. The radiometric measurements are acquired and processed following the method described in Zibordi et al. (2011). To increase the number of samples per unit depth, data are acquired using the multicast technique (D'Alimonte et al., 2010; Zibordi et al., 2004).

Multi-level data processing is achieved using the Software for the Elaboration of Radiometer Data Acquisition (SERDA) developed at GOS. The processing steps follow the consolidated protocols for the data reduction of in-water radiometry (Mueller and Austin, 1995; Zibordi et al., 2011). First, data are converted from digital counts into their physical units. A filter is applied to remove data with a profiler tilt angle larger than $5^{\circ}$. In order to reduce the influence of light variability during the measurements, data from each sensor are normalized by the above-water downwelling irradiance. A least-squares linear regression is performed on the log-transformed normalized data, whose slope determines the diffuse attenuation coefficients of spectral upwelling radiance $(\operatorname{Kl}(\lambda))$, spectral upwelling irradiance $(\operatorname{Ku}(\lambda))$, and spectral downwelling irradiance $(\operatorname{Kd}(\lambda))$; the exponents of the intercepts are the subsurface quantities $(\operatorname{Lu}(0-, \lambda)$, $\operatorname{Eu}(0-, \lambda)$, and $\operatorname{Ed}(0-, \lambda))$. Outliers due to wave perturbations are removed and identified in points differing, by default, more than 2 standard deviations from the regression line. The depth layer normally considered relevant for the extrapolation to the surface is $0.3-3 \mathrm{~m}$, but can be changed on the basis of the characteristics of each profile. The upwelling subsurface quantities (i.e. $\mathrm{Lu}(0-, \lambda), \mathrm{Eu}(0-, \lambda))$ are also corrected for the self-shading effect following Zibordi and Ferrari (1995) and Mueller and Austin (1995) using the ratio between diffuse and direct atmospheric irradiance and seawater absorption. Using the primary subsurface quantities, it is then possible to derive additional products such as the $Q$ factor at nadir $\left(\mathrm{Qn}\left(0^{-}, \lambda\right)=\mathrm{Eu}\left(0^{-}, \lambda\right) / \mathrm{Lu}\left(0^{-}, \lambda\right)\right)$, the remote sensing reflectance $(\operatorname{Rrs}(\lambda)=0.543 \cdot \operatorname{Lu}(0-, \lambda) / \operatorname{Es}(0, \lambda))$, or the normalized water-leaving radiance $(\operatorname{Lwn}(\lambda)=\operatorname{Rrs}(\lambda) \cdot \operatorname{E} 0(\lambda)$ with $\mathrm{E} 0(\lambda)$ being the extra-atmospheric solar irradiance; Thuillier et al., 2003).
Fluorimetric measurements associated with CTD casts are used to increase the depth resolution of the HPLC-derived chlorophyll. These calibrated fluorimetric casts are then used to compute the optically weighted pigment concentration (OWP) as already reported in Volpe et al. (2007).

In addition to the MedBiOp dataset collected by GOS over the Mediterranean Sea, two fully independent datasets collected at fixed locations are included for the validation in this study: Rrs data estimated from above-water measurements at the Aqua Alta Oceanographic Tower (AAOT) as part of the AERONET-OC network in the northern Adriatic Sea (Zibordi et al., 2009) and Rrs data from the BOUSSOLE buoy located in the Ligurian Sea (Antoine et al., 2008; Valente et al., 2016). Moreover, for the validation of the diffuse attenuation coefficient we use the independent BGC-Argo float dataset from Organelli et al. (2016).

\subsection{Satellite data processing chain}

As mentioned, GOS operates two different processing chains (Fig. 2) for NRT-DT and REP data production. The input of both processing chains is the spectral Rrs downloaded from upstream data providers. Hence, in both cases, the atmospheric correction is not part of these processing chains. This approach differs from the previous regional processing chains, which started from L1 (Volpe et al., 2007, 2012), as updates by the space agencies in the L1 to L2 processor resulted in a delay of months before it could be taken up in the operational processing chain.

As schematically shown in Fig. 2, the NRT-DT chain consists of four parts aimed at populating a 2-year rolling archive with multi-sensor Level 3 data at daily temporal resolution (hereafter referred to as Multi). The rolling archive includes the L3 obtained by the NRT L2 data (i.e. processed with preliminary ancillary data, calibration known at the time of acquisition, preliminary climatology, and so on), which are superseded, generally after 1 month, by the L3 produced in DT mode. Thus, the processing chain is exactly the same for the two modes, NRT and DT, the only changes being the input data from space agencies. Data in the rolling archive are homogeneous in terms of format and processing software, meaning that if, for any reason, a change is made on the processing chain, the entire rolling archive is processed back for consistency. The ingested L2 data (NASA processing version R2018.0) currently derive from MODIS Aqua and VIIRS sensors only. L2 data are downloaded from the Ocean Biology Processing Group (OBPG) at NASA, which uses the $12 \mathrm{gen}$ processor for the atmospheric correction in its default parameterization (Mobley et al., 2016). The NRT-DT chain involves the pre-processing of different sensors with different wavelengths (as detailed in Sect. 2.2.1) that are then merged together over a common set of wavelengths (Table 1, Sect. 2.2.2). Section 2.2.3 provides a description of the algorithms for the satellite-derived $\mathrm{Chl}$ estimation and for the attenuation coefficient of light at $490 \mathrm{~nm}(\mathrm{Kd} 490)$. As detailed 


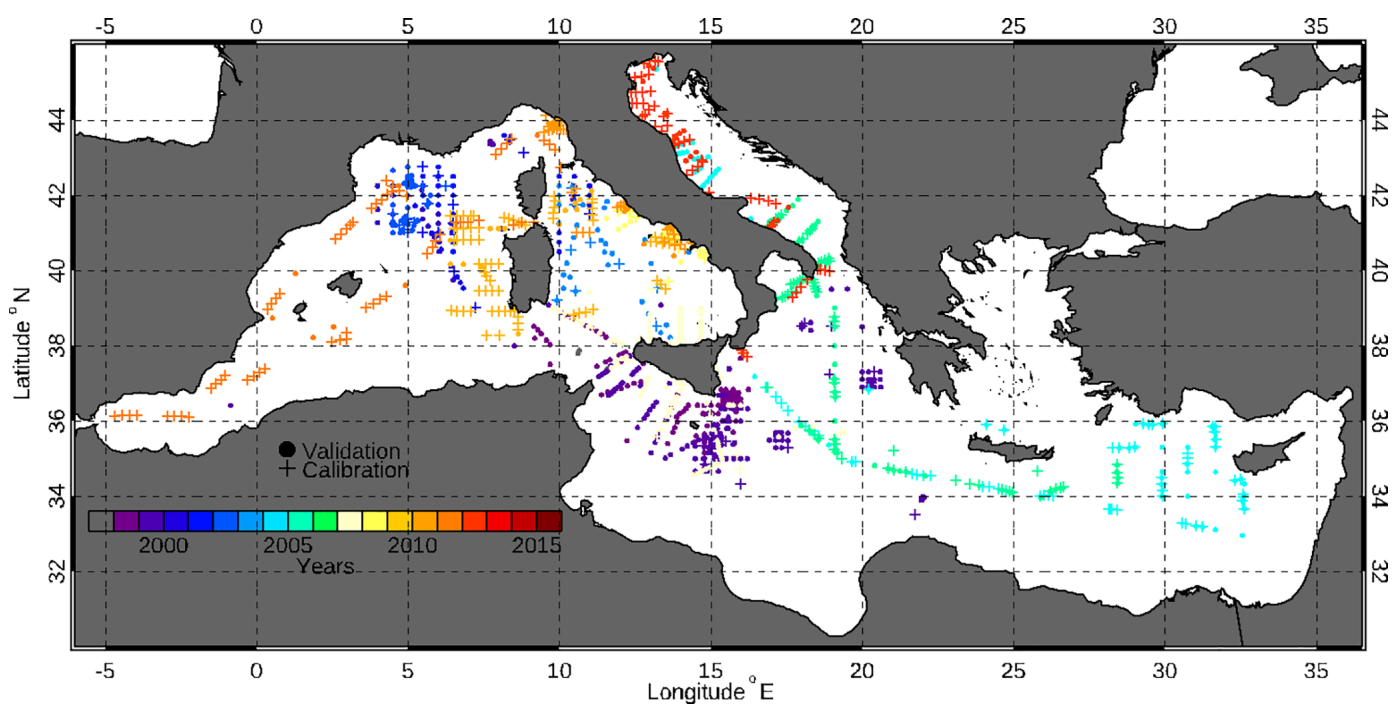

Figure 1. Study area and space-time distribution of the in situ MedBiOp dataset (1997-2016) used in this work. Dots identify the in situ stations used as sea-truth for satellite data validation, whereas crosses refer to the observations used to develop the regional OC algorithms.

Table 1. Overview of the available wavelengths from VIIRS, MODIS, MERIS, OLCI, and SeaWiFS sensors, those used to produce the REP dataset (available from PML), and those collected in situ. Target wavelengths of the band-shifting procedure are highlighted in grey. The column "in situ" refers to the bands of the $\mathrm{Lu}, \mathrm{Ed}$, and Es Satlantic radiometers used to compute the algorithm functional forms and described in the text (The Mediterranean Sea in situ bio-optical dataset: MedBiOp). To allow for a full satellite to in situ data comparison, the in situ data that are not directly measured (bands without the "x") are computed via band shifting.

\begin{tabular}{|c|c|c|c|c|c|c|c|}
\hline \multirow[t]{2}{*}{ Wavelength (nm) } & \multicolumn{5}{|c|}{ Sensors } & \multirow[t]{2}{*}{ REP } & \multirow[t]{2}{*}{ In situ } \\
\hline & VIIRS & MODIS & MERIS & OLCI & SeaWiFS & & \\
\hline 410 & $\mathrm{x}$ & & & & & & \\
\hline 412 & & $\mathrm{x}$ & $\mathrm{x}$ & & $\mathrm{x}$ & $\mathrm{x}$ & $\mathrm{x}$ \\
\hline 413 & & & & $\mathrm{x}$ & & & \\
\hline 443 & $\mathrm{x}$ & $\mathrm{x}$ & $\mathrm{x}$ & $\mathrm{x}$ & $\mathrm{x}$ & $\mathrm{x}$ & $\mathrm{x}$ \\
\hline 486 & $\mathrm{x}$ & & & & & & \\
\hline 488 & & $\mathrm{x}$ & & & & & \\
\hline 490 & & & $\mathrm{x}$ & $x$ & $\mathrm{x}$ & $x$ & $\mathrm{x}$ \\
\hline 510 & & & $\mathrm{x}$ & $\mathrm{x}$ & $\mathrm{x}$ & $\mathrm{x}$ & $\mathrm{x}$ \\
\hline 531 & & $\mathrm{x}$ & & & & & \\
\hline 547 & & $\mathrm{x}$ & & & & & \\
\hline 551 & $\mathrm{x}$ & & & & & & \\
\hline 555 & & & & & $\mathrm{x}$ & $\mathrm{x}$ & $\mathrm{x}$ \\
\hline 560 & & & $\mathrm{x}$ & $\mathrm{x}$ & & & \\
\hline 665 & & & $\mathrm{x}$ & $\mathrm{x}$ & & & $\mathrm{x}$ \\
\hline 667 & & $\mathrm{x}$ & & & & & \\
\hline 670 & & & & & $\mathrm{x}$ & $\mathrm{x}$ & \\
\hline 671 & $\mathrm{x}$ & & & & & & \\
\hline
\end{tabular}

later, inherent optical properties (IOPs: the absorption due to phytoplankton, $a_{\mathrm{ph}}$, and to detrital and dissolved matter, $a_{\mathrm{dg}}$, and the backscattering due to particles, $b_{\mathrm{bp}}$, all at $443 \mathrm{~nm}$ ) are used to align the different sensors over the common set of wavelengths. For this reason, the IOPs are an active part of the processing and are also made available to users as output of the chain.
For the REP processing, Rrs spectra over the common set of wavelengths (Table 1) are produced by the Plymouth Marine Laboratory (PML) using the OC-CCI processor version 3 (hereafter CCIv3; http://www.esa-oceancolour-cci. org/, last access: 7 February 2019), merging MERIS, MODIS Aqua, SeaWiFS, and VIIRS data. As fully detailed in CCI (2016a), SeaWiFS and VIIRS data are derived from the OBPG chain using the 12 gen processor, while MERIS and 


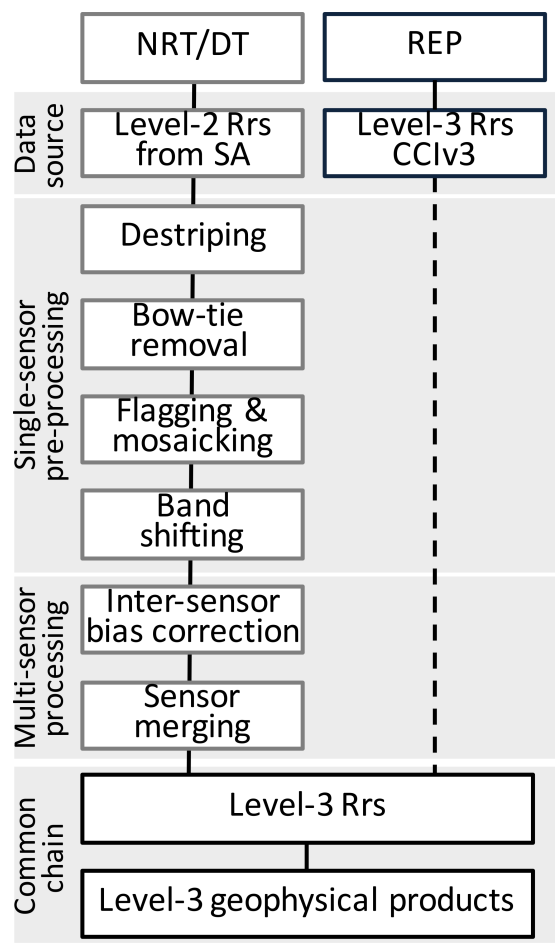

Figure 2. Flow chart of the processing chains for the two data production lines: NRT-DT and REP modes. SA stands for space agencies. The dashed vertical line indicates that the CNR REP processing mode only involves the application of the regional fine-tuned algorithms for the retrieval of the geophysical quantities.

MODIS Aqua data are processed with the POLYMER atmospheric correction processor (Steinmetz et al., 2011). At the moment of writing, the CCIv3 is based on the NASA reprocessing R2014.0. Within CMEMS, PML runs the regional CCIv3 processor at $1 \mathrm{~km}$ resolution rather than at $4 \mathrm{~km}$ as for the global OC-CCI dataset. In this work, with CCIv3 we will refer to both the processor and the derived Rrs exclusively made for CMEMS, whereas with REP we will refer to the output of this chain, Chl and Kd490. These are consistently retrieved with the same algorithms as in the NRT-DT chain (Sect. 2.2.3), updated on a yearly basis, and available to users on the CMEMS web portal (http://marine.copernicus.eu/, last access: 7 February 2019).

As shown in Fig. 1, most of the in situ data used for the validation analyses do not overlap the 2-year rolling archive (2017-2018 at the time of writing). Hence, for the sole scope of the product validation, the NRT-DT production chain is used to process the entire satellite data archive, including SeaWiFS and MERIS data. SeaWiFS data are obtained from NASA-OBPG (R2018.0), while MERIS data are from the ESA third reprocessing with POLYMER, made available by PML.

\subsubsection{NRT-DT single-sensor pre-processing}

Once downloaded and quality checked, single-sensor L2 data are fed into the pre-processing chain to harmonize data from different sensors in terms of format, projection, and most of all in terms of a common set of wavelength bands. The quality checks that are operationally performed soon after the download are associated with the integrity of data files or their effective coverage over the region of interest (the Mediterranean Sea in this case). Moreover, the preprocessing also takes care of sorting out issues that may affect one sensor only such as the de-striping procedure or the removal of the bow-tie effect.

\section{De-striping}

An important task, operationally performed over both MODIS Aqua and NPP-VIIRS images, is the application of a de-striping procedure over L2 products to remove instrument-induced stripes. These two sensors scan the Earth surface via a rotating mirror system that reflects the surface radiance to band detectors. Stripes originate from two hardware problems: (i) the two sides of the mirror are not exactly identical, and (ii) the band detector degradation is not homogeneous. De-striping correction is performed by applying the method developed by Bouali and Ignatov (2014) and adapted to ocean colour products by Mikelsons et al. (2014). The procedure splits the image into a stripe-affected and a stripe-free part. The stripe-affected part is then passed through a filter that removes the stripes and is then added back to the stripefree component to produce the final de-striped image. The definition of striped and de-striped domains is achieved by measuring the gradients (both along and across the scan) and by selecting as "striped" the ones below the predetermined threshold values.

\section{Removal of the bow-tie effect}

As sensor detectors have constant angular resolution, the sampled Earth area, i.e. the dimension of the pixel at the ground, increases with the scan angle. This results in consecutive scans to overlap away from nadir, in turn giving the entire scan the shape of a bow tie. Differently than other sensors such as MODIS Aqua, the aggregation scheme on board VIIRS removes this effect through a combination of aggregation and deletion of overlapping pixels, resulting in a series of rows of missing values at the edge of each L2 granule. These lines can be identified through the bow-tie removal flag of 12 gen (BOWTIEDEL). In this production chain and in view of the sensor merging, these missing values are filled in by linear interpolation. Alas, the L2 flags associated with these pixels are not updated due to the difficulty of interpolating binary fields. 


\section{Flagging and mosaicking}

Each L2 granule is quality checked via the application of the L2 flags provided by space agencies. The L2 flags result from the atmospheric correction procedure and provide the sensing conditions at pixel scale. The flags currently applied are those of the OBPG standard processing (https://oceancolor.gsfc.nasa.gov/atbd/ocl2flags/, last access: 7 February 2019), except for the atmospheric correction failure (ATMFAIL) flag that is not applied to VIIRS because it overlaps for almost all water pixels over the Mediterranean Sea with BOWTIEDEL, thus effectively thwarting the interpolation of the lines affected by the bow-tie effect. From a test over 645 granules $(3200 \times 3232$ pixels each) acquired over the Mediterranean Sea in 100 days (10 April to 18 July 2018 ) it was found that only in 31 pixels was the atmospheric correction failure flag raised for pixels not affected by bowtie deletion or any of the other OBPG standard flags.

Moreover, each granule undergoes a further quality check by removing all isolated pixels (defined as pixels with a meaningful value entirely surrounded by pixels with a missing value) and by filling in all isolated missing pixels (defined as pixels with a missing value entirely surrounded by pixels with a meaningful value) with the median value of their surrounding valid pixels. All Rrs spectra are further checked for the presence of negative values, which may occur in the blue part of the spectrum due to the failure of the atmospheric correction; one negative value within the spectrum (excluding the $670 \mathrm{~nm}$ band) is enough for the entire spectrum to be rejected. All available granules for each day are remapped at $1 \mathrm{~km}$ resolution on the equirectangular grid covering the Mediterranean Sea $\left(6^{\circ} \mathrm{W}-36.5^{\circ} \mathrm{E}, 30-46^{\circ} \mathrm{N}\right)$. All re-gridded granules from the same sensor and from the same day are mosaicked together by simple averaging into a single file containing the remote sensing reflectance at nominal sensor wavelengths.

\section{Band shifting}

At the scale of the pixel, the goal is to merge single-sensor Rrs spectra into a single spectrum. The idea is that from the Rrs spectrum one can easily derive, directly or indirectly, all the geophysical parameters of interest not only for the ocean colour community, but also for the wider biogeochemical scientific community. One of the problems of multi-sensor merging is the different set of bands from the various ocean colour sensors that have to be merged. Some bands are coincident $(443 \mathrm{~nm})$, others may differ by a few nanometres (486 and 488 or 410 and $412 \mathrm{~nm}$ ), and others can be significantly different (e.g. the green bands of MODIS Aqua, SeaWiFS, and OLCI, which are 547, 555, and $560 \mathrm{~nm}$, respectively; Table 1). A technique to collapse the various spectra on a predefined set of bands is thus essential for multi-sensor merging; with this aim the band-shifting method described by Mélin and Sclep (2015) was implemented here with the ap- plication of the quasi-analytical algorithm (QAA version 6; Lee et al., 2002, and following updates http://www.ioccg. org/groups/Software_OCA/QAA_v6_2014209.pdf, last access: 7 February 2019) in forward and backward modes. Rrs is related to the absorption and scattering properties of the medium, which in turn are given by the additional contributions of all the medium components (seawater, particulate, and dissolved matter). Starting from the Rrs at the sensor native wavelengths and from the characteristic spectral shapes of the IOPs, the QAA allows for the estimation of the IOPs at target wavelengths. The QAA is then applied in forward mode to estimate the Rrs at these bands. In general, the band-shifting technique is meant to be applied when source and target wavelengths differ by a few nanometres. However, there can be cases in which the spectral distance between source and target wavelengths is larger, i.e. the estimation of the band at $510 \mathrm{~nm}$ from MODIS Aqua at 488 and $531 \mathrm{~nm}$. In this case, the band shifting is operated twice: first from 488 towards $510 \mathrm{~nm}$ and second from $531 \mathrm{~nm}$ towards $510 \mathrm{~nm}$. The "final" value is computed as the weighted average of the two, the weight being the inverse of the spectral distance. The accuracy of QAA retrievals over the Mediterranean Sea was assessed with a limited number of observations by Pitarch et al. (2016), who found that $b_{\mathrm{bp}}$ at $555 \mathrm{~nm}$ was retrieved within $5 \%$ of in situ measurements across open and coastal waters. This approach produces a set of common bands (in Table 1) for all sensors and allows for the daily merging of the Rrs from which it is then possible to derive geophysical products. The uncertainty introduced by band shifting is estimated in most cases at well below $5 \%$ of the reflectance value (with averages of typically $1 \%-2 \%$ ), especially for open ocean regions (Mélin and Sclep, 2015).

\subsubsection{NRT-DT multi-sensor processing: Rrs spectra}

Once single-sensor spectra are homogeneous in terms of wavebands, it is possible for the Rrs from the available sensors to be merged together into single images. The output is a set of six Rrs images, each of which is treated as an individual image independently from the other Rrs bands of the spectrum.

\section{Differences between MODIS and VIIRS}

At pixel scale, several reasons can be at the base of the differences between two observations. The geometry of the observations constitutes an issue that is under the control of the atmospheric correction scheme. Since this part of the processing is performed by space agencies, this issue is rarely accounted for in the context of L3 multi-sensor merging, which instead only considers radiometric quantities as fully normalized (Maritorena and Siegel, 2005). The differences between Rrs retrieved by MODIS and VIIRS vary with the wavelength (Fig. 3). The distribution of the Rrs ratio at $670 \mathrm{~nm}$ shows the most negative kurtosis. At $412 \mathrm{~nm}$, the median 
Rrs ratio ranges between 0.7 and 1 , while at $443 \mathrm{~nm}$ it improves and narrows to 0.85 and 1.05 with MODIS being in general below VIIRS. For the three other bands $(490,510$, and $555 \mathrm{~nm}$ ), the Rrs ratio distribution displays the narrowest spread around 1 with the median values ranging between 0.9 and 1.1. Moreover, a pixel is sampled with different geometry (scattering angle) and not exactly at the same time by the two sensors; in the Mediterranean Sea, the differences between the two sensor time overpasses do not exceed $1 \mathrm{~h}$. Here, we found that the discrepancy between the two Rrs spectra cannot be ascribed to differences in the overpass times and/or to the geometry of the observation (Fig. 3). We argue that there must be other factors responsible for the observed differences such as inter-sensor calibration or even the various bands used for operating the single-sensor atmospheric correction (eliciting different responses by the atmospheric correction code and its assumptions and/or simplifications). All these issues should be addressed before any sensor merging can effectively be performed (Sathyendranath et al., 2017).

\section{Inter-sensor bias correction}

Before merging all the available sensors together at any given time, their Rrs spectra are individually bias-corrected with respect to their references as detailed below. Here, we extend the method developed within OC-CCI for reducing intersensor bias (CCI, 2016b), as this is a propaedeutical step to the proper merging of data collected from different sensors. In practice, when two or more sensors are available for the same period, one sensor is taken as a reference and the others are bias-corrected to the reference. For the intersensor bias to be corrected, daily climatological bias maps are computed at the same spatial resolution of the source data (e.g. $1 \mathrm{~km}$ ). During the SeaWiFS era, the method is applied to SeaWiFS-MODIS-MERIS sensors having SeaWiFS as a reference. From 2010 onward, the method is applied to the coupled MODIS-VIIRS using MODIS as a reference after its bias with SeaWiFS is corrected. The climatological bias maps were computed using data from 2003 to 2007 for the SeaWiFS era and from 2012 to 2014 for the other.

Briefly, the OC-CCI scheme to compute the daily climatological bias maps is the following.

1. Over the periods of reference, for each sensor, a rolling temporary daily average map of Rrs is computed (simple mean) over the period of 7 days: the data day itself plus 3 days before and 3 days after.

2. For each day, the ratio between the temporary average Rrs maps from the various sensors is computed.

3. This allows for the calculation of 365 daily climatology maps of the ratio between each pair of missions over the periods of reference.

4. To increase map coverage, smoothing of the daily climatology bias maps over a temporal window of $2 \mathrm{~N}+$
1 days (with $N=60$ ) is computed following Eqs. (1) and (2):

$\delta(d, x, y)=\frac{\sum_{i=-N}^{N} w_{i} \delta_{i}(d+i, x, y) \theta_{i}}{\sum_{i=-N}^{N} w_{i} \theta_{i}}$,

with

$w_{i}=\frac{N+1-|i|}{N+1}$,

where $\delta(d, x, y)$ is the daily bias map climatology, and $\theta_{i}=1$ if $\delta_{i}$ is associated with a valid value and zero otherwise. The value of the weight, $w$, decreases from 1 for the same day, to $N / N+1$ for the days before and after, to $1 / N+1$ for the first and last days of the $\pm N$ day window.

The way the daily climatological bias maps are computed here differs from the OC-CCI technique. First, the rolling temporary 7-day average (point 1 of the OC-CCI method described above) is computed here using Eqs. (1) and (2), with $N=3$. The smoothing of the daily climatology bias maps is obtained by applying a weighting function (as point 4 of the OC-CCI method described above) in both space and time, contemporaneously. The spatial kernel of the $3 \times 3$ box centred to the pixel is defined as in the table below.

\begin{tabular}{|l|l|l|}
\hline 0.25 & 0.50 & 0.25 \\
\hline 0.50 & 1.00 & 0.50 \\
\hline 0.25 & 0.50 & 0.25 \\
\hline
\end{tabular}

The cumulative effect of these two weighting functions is given by their cross-product.

Furthermore, the method was not applied to the $670 \mathrm{~nm}$ band because the percent difference between SeaWiFS and in situ observations at $670 \mathrm{~nm}$ is 1 or 2 orders of magnitude larger than the blue-green counterparts in both oligotrophic and mesotrophic conditions (MedBiOp, BOUSSOLE) (Sect. 3). Moreover, the number of matchups between SeaWiFS and all the available in situ data (MedBiOp, BOUSSOLE, and AAOT) at $670 \mathrm{~nm}$ is $\sim 40 \%$ of those in the bluegreen spectral region (data not shown).

\section{Sensor merging}

When merging data from two or more sensors, three possible conditions can occur: (i) the pixel is observed from more than one sensor, (ii) the pixel is observed from one sensor only, or (iii) the pixel is in no clear-sky condition or is masked out because of any of the operational L2 flags from all sensors. In the latter case the pixel is assigned the missing value. In the former two conditions the merging is not straightforward because it strongly depends on the ability to reduce the inter-sensor bias to zero. When the pixel is sampled by one sensor only but the surrounding pixels by more than one or by the other sensors, there is an increasing probability of introducing artefacts or spatial gradients, which in 


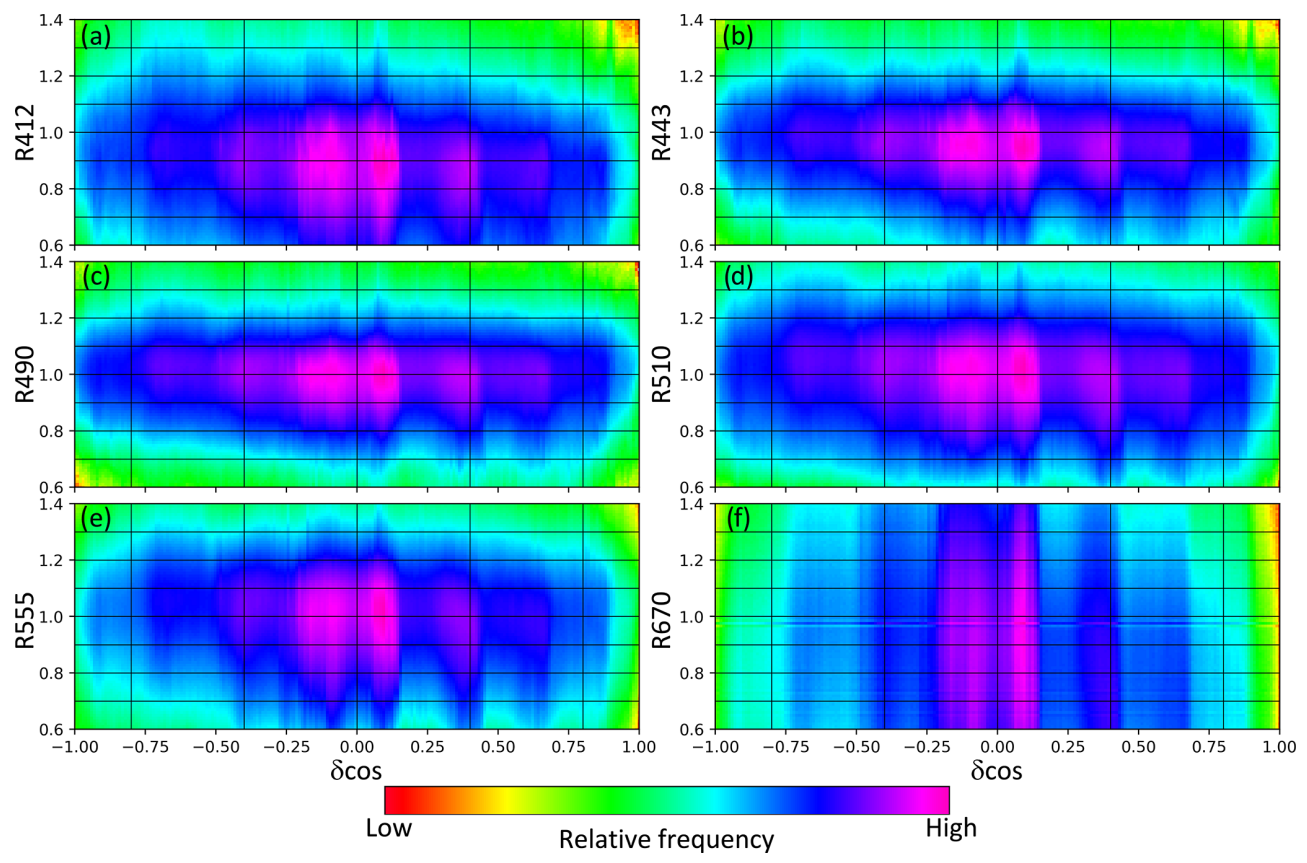

Figure 3. 2-D frequency histogram of the daily Rrs ratio ( $R$, on the $y$ axis) and the difference of the cosine of the scattering angle $(\delta$ cos) between MODIS Aqua and VIIRS for each of the six bands of the Multi product $(2012-2017)$. The scattering angle $\left(\Theta_{\mathrm{S}}\right)$ is defined as $\Theta_{\mathrm{S}}=$ $\frac{180}{\pi} \arccos \left(-\cos \left(\frac{\pi}{180} \theta_{0}\right) \cos \left(\frac{\pi}{180} \theta_{\mathrm{S}}\right)-\sin \left(\frac{\pi}{180} \theta_{0}\right) \cos \left(\frac{\pi}{180} \varphi_{\mathrm{r}}\right)\right)$, with $\theta_{0}, \theta_{\mathrm{S}}, \varphi_{\mathrm{r}}$ being the solar and sensor zenith angles and the relative azimuth angle, respectively. $R$ exhibits substantial variability across the spectrum with the values shown in panels (a) and (f) presenting the larger differences. Overall, the median values of the Rrs ratios at the six bands are within the range 0.9-1.1. The noticeable feature is the lack of any dependency of $R$ from the geometry of the observation $(\delta \cos )$.

reality do not exist and are only the result of the merging procedure. To prevent the occurrence of such horizontal discontinuities, here we apply a smoothing procedure based on the use of a SeaWiFS daily climatology field, described in Volpe et al. (2018) and summarized below. First, the field from each sensor (Fig. 4a, b) is filled with the same relevant daily climatology (Fig. 4e; see below for more details about the climatology), as shown in Fig. 4c, d. Filling is performed as follows: for each sensor, the difference between the two fields (observed and climatology) is first computed in correspondence to coexisting values. Such a difference is propagated and smoothed all over the spatial domain. Missing observational values are replaced with the climatology corrected by the computed difference map. This prevents the generation of sharp gradients in the final merged product. At this stage, the simple average between all available climatology-filled sensor data is computed. Then all the non-clear-sky pixels are set to the missing value (Fig. 4f). This is the procedure operationally and currently applied to data acquired by MODIS Aqua and VIIRS to produce the multi-sensor Rrs product. It is important to note that features only present in the climatology, but not in the daily single-sensor images, are also absent in the merged product. In the example of Fig. 4, features of such a kind can be clearly identified in correspondence to the Strait of Bonifacio in the Tyrrhenian Sea, which extends eastwards in the climatology (Fig. 4e) but in none of the other fields (MODIS Aqua or VIIRS). Another example is given by the tongue of Modified Atlantic Water (Manzella et al., 1990) that penetrates the southern sector of the Sicily Channel towards the Libyan coasts, which is present in Aqua, VIIRS, and in the merged image, but not in the climatology. Similarly, the Rhône River plume, visible in the climatology as a small reddish spot, is absent from both single-sensor images and from the merged multi-sensor product.

After all bands are merged, single-pixel Rrs spectra are available (Fig. 5) for the geophysical products to be computed. Within this step, a mask is computed for keeping track of the single-sensor inputs to the multi-sensor product and added to the NetCDF files (Fig. 5b, d). The examples show two cases of blue and greener waters along the Spanish coast and in the northern Adriatic Sea, respectively. In both cases, the satellite Rrs benefiting from the bias correction are closer to the in situ measurements at all bands.

\section{Climatology}

As mentioned, the climatology provides spatial support for sensor merging. The climatology field is obtained from the 13 years of SeaWiFS data. This daily field has the same spatial resolution (nominally $1 \mathrm{~km}$ at nadir) and projection (cylindrical) as the operational field. These climatology maps were created using the data falling into a moving temporal 


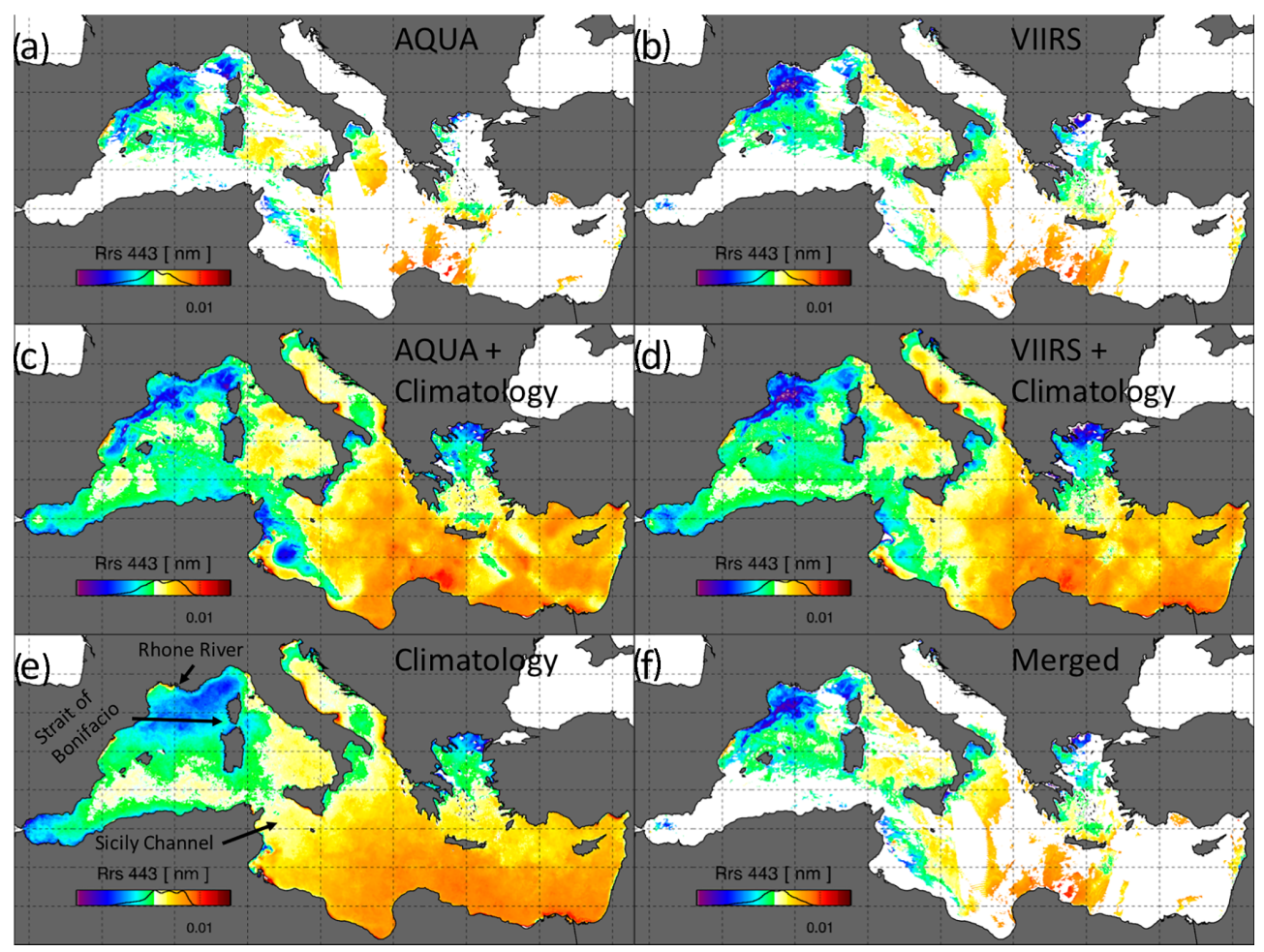

Figure 4. Example of how the merging of MODIS and VIIRS works. Rrs 443 from MODIS Aqua (a) and NPP-VIIRS (b) from 1 April 2012. Panels (c) and (d) are obtained by filling in panels (a) and (b) with daily climatology (e). The merged multi-sensor product is obtained after removal of the unseen pixels (f). Distribution histograms for each image are included in relevant colour bars.
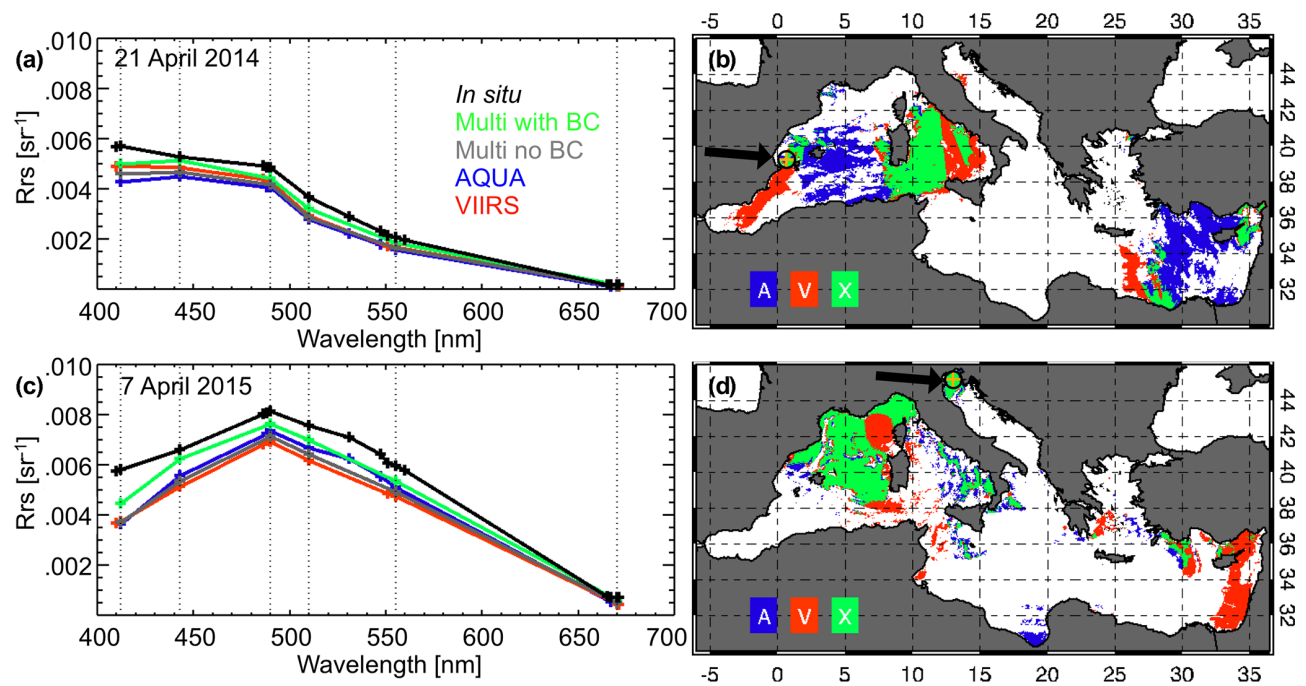

Figure 5. Rrs spectra from 21 April 2014 (a) from MODIS Aqua (A, blue), NPP-VIIRS (V, red), the merged multi-sensor product with the application of the bias correction (X, green) and without (grey), and the in situ measurements (black), all in correspondence to the in situ measurement location shown by the arrow in panel (b). The map in panel (b) is the sensor mask of the day on which the pixels sampled by MODIS Aqua only are shown in blue and those by NPP-VIIRS only in red; the pixels sampled by both sensors are shown in green. Panels (c) and (d) refer to the Rrs spectra and sensor mask from 7 April 2015, in the northern Adriatic Sea. 
window of \pm 5 days. A total of 5 days is deemed to be a good compromise between the need for filling the spatial domain and the de-correlation timescale of the $\mathrm{OC}$ data in the Mediterranean Sea; this has been estimated as being 3 days on average (the day on which the autocorrelation value is halved; Volpe et al., 2018). The resulting daily climatology time series includes the pixel-scale standard deviation, the average, the median, the modal, the minimum, and the maximum values. The next version of the NRT-DT processing chain will include a climatology field computed by taking into account the space-time-weighted averaging and a longer and more recent data time series.

\subsubsection{Level 3 geophysical products}

The input to all algorithms used to derive the various geophysical products is the Rrs spectrum, which in this context derives from the NRT-DT processing chain described above and from the CCIv3 processor. It should be noted that in L1 to $\mathrm{L} 2$ processing performed by the space agencies, the waterleaving radiance normalization scheme makes use of Chl values estimated with standard algorithms. The differences between standard Chl and MedOC4 estimates in the Mediterranean Sea might affect the accuracy of the resulting Rrs. However, in the context of L3 multi-sensor merging this inconsistency cannot be accounted for without performing the L1 to L2 processing in-house. The previous regional processing chains started from L1 and took this effect into account (Volpe et al., 2007, 2012). On the other hand, in the operational oceanography framework, the need to keep the L2 to L3 processing chain readily up to date imposes a trade-off between accuracy and timeliness.

As shown in Fig. 2, from this point on, the NRT-DT and the REP chains collapse as they both use the same algorithms for computing $\mathrm{Chl}, \mathrm{Kd}$, and the IOPs. The next sections explain how the various algorithms are derived and applied to Rrs data for their operational application.

\section{Chlorophyll $a$ concentration}

There are two main categories of $\mathrm{Chl}$ algorithms: empirical and semi-analytical. Even though the latter type now shows a performance comparable to that of empirical algorithms, these still remain more robust and are generally preferred in the operational context (e.g. NASA processing). Recently, Sathyendranath et al. (2017) discussed the characteristics that remote sensing data must have to be used in climate studies. They pointed out that semi-analytical algorithms would be preferred to empirical ones because they do not rely on past observations, which are not necessarily the best approximation for future observations (Dierssen, 2010). However, they still lack the robustness typical of the empirical family of algorithms (O'Reilly et al., 2000 among others).

Operational services such as CMEMS aim at providing data for a wide range of applications from the assimila- tion of open ocean observations into biogeochemical models (Teruzzi et al., 2014) to coastal monitoring programmes (such as the Marine Strategy Framework Directive; e.g. Colella et al., 2016). Unfortunately, there is not yet a unique Chl algorithm able to perform with the same accuracy across different environments. For example, open ocean waters are prevalently dominated by phytoplankton cells and their products of degradation; these waters are well represented by chlorophyll concentration and are generally referred to as Case I waters (Morel and Prieur, 1977). On the other hand, the optical properties of coastal regions are more often influenced by various water constituents not necessarily covarying with phytoplankton and are referred to as Case II waters. Since the offshore extension of coastal waters may vary and be of several kilometres (pixels), depending on the sea and weather conditions (e.g. coastal filaments may extend several tens of kilometres in the open ocean), the adoption of static masks for the application of different algorithms would result in errors associated with the sharp fronts. One way to overcome this issue is to merge two $\mathrm{Chl}$ products into a single field after the exact identification of the two realms (Mélin et al., 2011; Volpe et al., 2012; Moore et al., 2014). At pixel scale, Rrs spectra are translated into Chl twice: assuming the entire satellite scene to belong to Case I and to Case II waters, each with its own algorithm. Then, the water type identification follows the method developed by D'Alimonte et al. (2003), which uses the Mahalanobis distance between the satellite spectrum and the in situ reference spectra (in terms of the mean values and the covariance matrices of the two experimental datasets). For Case I Chl reference, D'Alimonte et al. (2003) used a former version of the current NOMAD dataset (Werdell and Bailey, 2005). In this work, for Case I and Case II waters, the MedOC4 (Volpe et al., 2007) and CoASTS (Berthon et al., 2002; Zibordi et al., 2002) datasets are used, respectively. This approach is one step towards the need of the scientific community to deal with products performing equally well in both water types, or at least to know where the first ends and the second starts (Sathyendranath, 2011, OC-CCI user consultation). To also address the latter point evidenced by the OC-CCI user consultation, a water type mask resulting from the Case I-Case II merging step is conveniently stored into the NetCDF files and made available to users. Thus, two different algorithms are used to derive $\mathrm{Chl}$ in the two optical domains: the ADOC4 algorithm (D'Alimonte and Zibordi, 2003) is used for the Case II domain, while the algorithm for Case I is the subject of the next paragraph.

\section{Mediterranean Sea - MedOC4 - Case I}

The algorithm used to retrieve $\mathrm{Chl}$ in the Case I waters of the Mediterranean Sea is an updated version of the MedOC4, a regionally parameterized maximum band ratio (Volpe et al., 2007). Figure 6a shows both the regional and the global algorithm (OC4v6; https://oceancolor.gsfc.nasa. 
gov/atbd/chlor_a/, last access: 7 February 2019) functional forms superimposed to the in situ observations collected in the Mediterranean Sea. The Mediterranean Sea tends to be "greener" than the Pacific and Atlantic oceans for any Chl values due to higher CDOM concentrations (Volpe et al., 2007, and references therein). Considering that the empirical algorithms are the expression of the in situ data from which they are derived, this figure provides a means for understanding the need to regionalize the algorithms to avoid the significant $\mathrm{Chl}$ overestimation that would be obtained with the global algorithm, as already fully documented in Volpe et al. (2007, and references therein).

An important point that has to be borne in mind is that the colour of the ocean, in terms of maximum band ratio (MBR), explains $74 \%$ of the entire phytoplankton variability, as expressed by the determination coefficient $\left(r^{2}\right)$ between the chlorophyll concentration and MBR (Fig. 6a). This points to the importance (more than $25 \%$ ) of the second-order variability of the ocean colour signal (Brown et al., 2008) that should be accounted for by future versions of the operational algorithms, in line with the recent recommendation about the use of ocean colour data for climate studies (Sathyendranath et al., 2017).

\section{Diffuse attenuation coefficient - Kd490}

Figure $6 \mathrm{~b}$ (red dots) shows the in situ diffuse attenuation coefficient of light at $490 \mathrm{~nm}$ as a function of the Rrs ratio $(R=$ $\log _{10}(\operatorname{Rrs} 490 /$ Rrs555)) collected in the Mediterranean Sea. Superimposed to the in situ dataset is also the algorithm functional form (turquoise line) used in the OBPG processing at global scale (https://oceancolor.gsfc.nasa.gov/atbd/kd_490/, last access: 7 February 2019). It is clear that the global algorithm only marginally overlaps the in situ data, thus prompting a regional dedicated algorithm to be developed. The black line is the in situ data best fit computed as a fourth-power polynomial expression of the Rrs ratio between 490 and $555 \mathrm{~nm}$.

\subsection{Validation framework}

The validation of the satellite products was carried out by pairwise comparison with the in situ observations: $\mathrm{Chl}$ and apparent optical properties, e.g. Kd490 and Rrs. For determining collocation between in situ and satellite data records all measurements acquired on the same day were used, as L3 data used in this study do not preserve the time information. Then, similarly to Zibordi et al. (2012), the median values are extracted from a $3 \times 3$ box centred on the in situ measurement coordinates only in the presence of at least five valid values and a coefficient of variation smaller than $20 \%$. Bailey and Werdell (2006) use a narrow time window for determining coincidence (i.e. no more than \pm 3 h); Fig. S1 in the Supplement presents the percent difference between satellite and in situ Rrs for time windows ranging between \pm 1 and $\pm 8 \mathrm{~h}$, assuming 10:00 am UTC as the satellite overpass time. The range of variability of the relative difference is always within $1 \%$, confirming recent results from Barnes et al. (2019).

The uncertainty associated with the in situ data is due to several factors, e.g. sea conditions and operator ability, which in turn can introduce several contamination factors; hence, here we consider satellite and in situ observations to both be affected by uncertainties (Loew et al., 2017). Thus, for the matchup analysis, a type- 2 regression (also called orthogonal regression) is implemented here (Laws and Archie, 1981). The statistical parameters for the assessment of satellite versus in situ data are listed in Table 2. For log-normally distributed variables (such as $\mathrm{Chl}$ and $\mathrm{Kd} 490$ ) both datasets are log-transformed prior to computing the slope $(S)$, the intercept (I), and the determination coefficient. A good match between the two observations is achieved when $S$ is close to 1 and $I$ is close to zero. The RMSD is the average distance of a data point from the fitted line, measured perpendicular to the regression line. RMSD and bias have the same units as the data from which they are derived.

\section{Results and discussion}

This section provides the validation analysis for the operational NRT-DT retrievals of Rrs and Chl with the multisensor merging approach. The NRT-DT products (multiproducts) are available in the CMEMS catalogue as a rolling archive spanning 2 years, prior to which REP products are available instead. As already mentioned, since most of the in situ data used for the validation analyses were collected earlier than 2017 (2 years ago at the time of writing), we used the NRT-DT production chain described in Sect. 2.2 to process the entire satellite data archive, hence generating a consistent DT dataset. The validation of the REP products based on the CCIv3 is also included for comparison.

\subsection{Temporal trend}

In this context and with the general aim of identifying any temporal dependence of the computed statistics, the analysis was made comparing the satellite products with spacetime-collocated in situ measurements for each campaign separately and for the whole dataset. No significant temporal behaviour emerged from the analysis (results not shown), highlighting the fact that both in situ and satellite data are homogeneous in time and well calibrated. Similar results were recently obtained at global scale by Sathyendranath et al. (2017).

\subsection{Matchup - Rrs single sensors, multi-sensor}

Figure 7 shows the relative difference between satellite and MedBiOp Rrs spectra. Satellite Rrs values at all available bands for each sensor are compared with the same in situ Rrs bands (Table 1). In general, the Rrs in the blue bands 

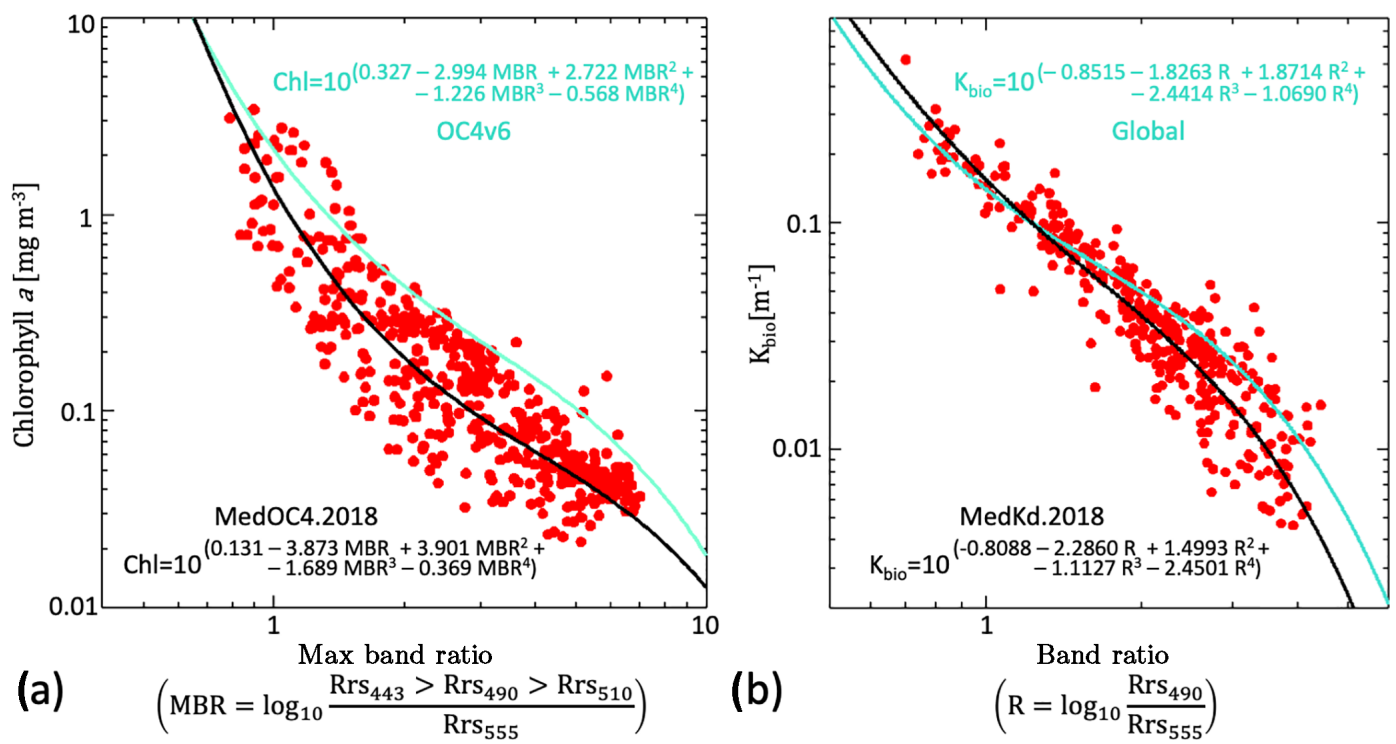

Figure 6. (a) Algorithm for chlorophyll retrieval over the Mediterranean Sea. The maximum band ratio (MBR) is shown on the $x$ axis; it is the $\log _{10}$ ratio between the maximum value among the three bands in the blue $(443,490$, and $510 \mathrm{~nm})$ and the one in the green part of the light spectrum $(555 \mathrm{~nm})$. Red dots $(N=509)$ are the in situ bio-optical data (MedBiOp, whose location is shown in Fig. 1) used to compute the operational algorithm (black line). As a means of comparison the global algorithm (OC4v6; https://oceancolor.gsfc.nasa.gov/atbd/chlor_a/, last access: 7 February 2019) functional form is also superimposed (turquoise line). (b) Algorithm for the retrieval of the diffuse attenuation coefficient, Kd490, over both the Mediterranean Sea (black line) and the global ocean (turquoise line). The global algorithm is the SeaWiFS (https://oceancolor.gsfc.nasa.gov/atbd/kd_490/, last access: 7 February 2019). Red dots $(N=366)$ are the in situ measurements over the Mediterranean Sea. Kd490 is the sum of Kbio and the attenuation due to pure seawater (0.0166; Mueller, 2000).

(443 and $490 \mathrm{~nm}$ ) performs better than those at $412 \mathrm{~nm}$ or those in the green region (510 and $555 \mathrm{~nm})$. As mentioned above, SeaWiFS, MODIS Aqua, and VIIRS are all processed with the 12 gen processor, so it is not surprising that these three sensors display a common spectral behaviour with respect to in situ observations. On the other hand, MERIS is the only one exhibiting a positive difference with respect to in situ observations for the 412 and 443 bands. This is likely due to the different processing (performed by ESA) for the L1 to L2 processing of MERIS (see Sect. 2.2 for details). Apart from the $670 \mathrm{~nm}$ band (RPD of $76 \%$ ), SeaWiFS performs generally better than the other sensors, thus supporting the choice as a reference sensor for the blue-green spectral range. All other satellite data never exceed $15 \%$ relative difference when compared with in situ observations at basin scale (Tables S2-S7). A noticeable feature presented in Fig. 7 is the wide variability of the computed statistics (given by the standard deviation bars) highlighting the fact that the satellite data presented here do not substantially differ from the in situ observations. Table 3 shows the full statistics for the MultiRrs product.

One of the main reasons for merging data from different sensors is to enhance the domain coverage by reducing the influence of both cloud coverage and generally flagged or masked pixels as well as the out-of-satellite-swath areas; in all cases the use of a multi-sensor approach increases the probability of valid clear-sky observations. Figure 8 shows

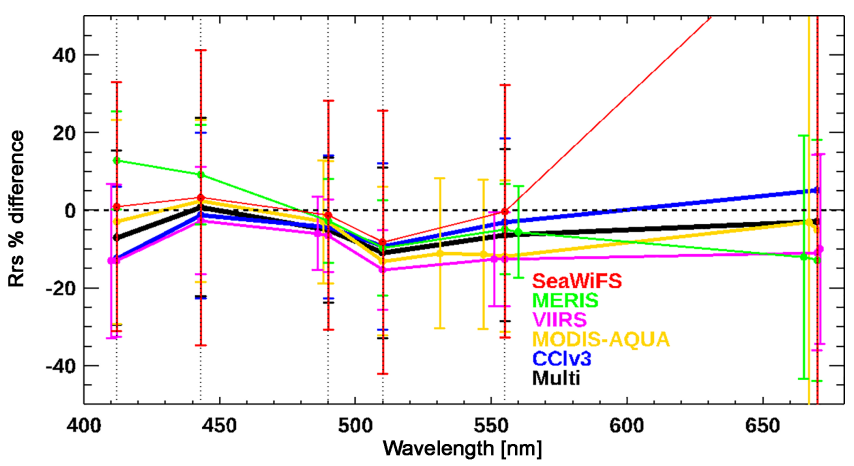

Figure 7. Relative difference between satellite and MedBiOp Rrs spectra for MODIS Aqua (yellow), NPP-VIIRS (magenta), SeaWiFS (red), MERIS (green), OC-CCI (blue), and the multi-sensor product developed and described in this work (black). Vertical bars represent 1 standard deviation from the average RPD value. Target wavelengths are marked with vertical dotted lines.

the time series of the percent basin coverage for four single sensors (SeaWiFS, MERIS, MODIS Aqua, and VIIRS) and the Multi product. The number of clear-sky pixels for the Multi product is on average larger than that of the single sensors by as much as $40 \%$ (Fig. 8), with minimum impact during winter and maximum at summertime. The difference between periods of maxima and minima somehow reflects the cloud cover influence over the multi-sensor product, with 
Table 2. Metrics used to compare the estimated (satellite-based) dataset $X^{\mathrm{E}}$ to a reference (measured in situ) dataset $X^{\mathrm{M}}$. A more comprehensive table of metrics is provided in the Supplement (Table S1). In the units column, G stands for geophysical and refers to $\mathrm{sr}^{-1}, \mathrm{~m}^{-1}$, or $\mathrm{mg} \mathrm{m}^{-3}$ when the statistics are associated with $\mathrm{Rrs}, \mathrm{Kd}$, or Chl, respectively.

\begin{tabular}{lll}
\hline Name & Units & Definition \\
\hline Type-2 slope & Geophysical & $S=\frac{\sum_{i=1}^{N}\left(X_{i}^{\mathrm{E}}-\bar{X}_{i}^{\mathrm{E}}\right)^{2}-\sum_{i=1}^{N}\left(X_{i}^{\mathrm{M}}-\bar{X}_{i}^{\mathrm{M}}\right)^{2}+\left[\left\{\sum_{i=1}^{N}\left(X_{i}^{\mathrm{E}}-\bar{X}_{i}^{\mathrm{E}}\right)^{2}-\sum_{i=1}^{N}\left(X_{i}^{\mathrm{M}}-\bar{X}_{i}^{\mathrm{M}}\right)^{2}\right]^{2}+4\left[\sum_{i=1}^{N}\left(X_{i}^{\mathrm{E}}-\bar{X}_{i}^{\mathrm{E}}\right)\left(X_{i}^{\mathrm{M}}-\bar{X}_{i}^{\mathrm{M}}\right)\right\}^{2}\right]^{1 / 2}}{2 \sum_{i=1}^{N}\left(X_{i}^{\mathrm{E}}-\bar{X}_{i}^{\mathrm{E}}\right)\left(X_{i}^{\mathrm{M}}-\bar{X}_{i}^{\mathrm{M}}\right)}$ \\
\hline Type-2 intercept & Geophysical & $I=\bar{X}^{\mathrm{E}}-S \bar{X}^{\mathrm{M}}$ \\
\hline $\begin{array}{l}\text { Determination } \\
\text { coefficient }\end{array}$ & $r^{2}=\frac{\left[\sum_{i=1}^{N}\left(X_{i}^{\mathrm{E}}-\bar{X}_{i}^{\mathrm{E}}\right)\left(X_{i}^{\mathrm{M}}-\bar{X}_{i}^{\mathrm{M}}\right)\right]^{2}}{\sum_{i=1}^{N}\left(X_{i}^{\mathrm{E}}-\bar{X}_{i}^{\mathrm{E}}\right)^{2} \sum_{i=1}^{N}\left(X_{i}^{\mathrm{M}}-\bar{X}_{i}^{\mathrm{M}}\right)^{2}}$ \\
\hline $\begin{array}{l}\text { Root mean } \\
\text { square } \\
\text { difference }\end{array}$ & Geophysical & $\mathrm{RMSD}=\sqrt{\frac{\sum_{i=1}^{N}\left(X_{i}^{\mathrm{E}}-X_{i}^{\mathrm{M}}\right)^{2}}{N}}$ \\
\hline $\begin{array}{l}\text { Bias } \\
\begin{array}{l}\text { Relative percentage } \\
\text { percentage } \\
\text { difference }\end{array}\end{array}$ & Percent & $\mathrm{RPD}=100 \cdot \frac{1}{N} \sum_{i=1}^{N} \frac{X_{i}^{\mathrm{E}}-X_{i}^{\mathrm{M}}}{X_{i}^{\mathrm{M}}}$ \\
\hline $\begin{array}{l}\text { Absolute percentage } \\
\text { percentage } \\
\text { difference }\end{array}$ & Percent & $\mathrm{APD}=100 \cdot \frac{1}{N} \sum_{i=1}^{N} \frac{\left|X_{i}^{\mathrm{E}}-X_{i}^{\mathrm{M}}\right|}{X_{i}^{\mathrm{M}}}$ \\
\hline
\end{tabular}

Table 3. Statistics associated with the Multi-Rrs product $\left(\mathrm{sr}^{-1}\right)$ computed over the MedBiOp dataset. The same statistics associated with all products shown in Fig. 7 are provided in the Supplement (Tables S2 to S7).

\begin{tabular}{ccrcccrcc}
\hline Rrs & Slope & Intercept & $r^{2}$ & RMSD & Bias & RPD & APD & $N$ \\
\hline 412 & 0.99 & -0.0006 & 0.77 & 0.0015 & -0.00060 & -7 & 18 & 272 \\
443 & 0.86 & 0.0007 & 0.73 & 0.0013 & -0.00023 & 1 & 15 & 272 \\
490 & 0.65 & 0.0015 & 0.55 & 0.0013 & -0.00047 & -5 & 13 & 272 \\
510 & 0.65 & 0.0009 & 0.57 & 0.0013 & -0.00060 & -11 & 18 & 272 \\
555 & 0.68 & 0.0005 & 0.71 & 0.0012 & -0.00027 & -6 & 16 & 272 \\
670 & 1.19 & -0.0001 & 0.91 & 0.0002 & -0.00002 & -3 & 35 & 197 \\
\hline
\end{tabular}

the wintertime being characterized by both cloud cover and out-of-satellite swath, while the summer periods are mostly affected by out-of-satellite-swath masked areas. Moreover, the coverage is higher in the period 2002-2011 when SeaWiFS (until 2010), MODIS Aqua, and MERIS were operating simultaneously. Despite the loss in 2010 of SeaWiFS with its very wide swath, in all of 2011 the gain (turquoise line in Fig. 8) does not decrease substantially. After the loss of MERIS in 2012 the gain in the percent basin coverage dramatically decreases. Thus, the basin coverage depends on the number of available sensors but also on the relationships of the orbital parameters among the various OC missions.

The results in Fig. 7 are representative of the performances of the various satellite observations (both single sensors and multi-sensors) against the in situ measurements that were widely collected over the basin in the past 20 years: the MedBiOp dataset. Similarly, Fig. 9 shows the comparison of the two multi-sensor time series (Multi product and CCIv3) against three in situ datasets: the basin-scale dataset (MedBiOp) and two fixed-location datasets (Sect. 2.1), one of which is coastal (AAOT). In general, one could expect the mismatch between satellite and in situ observations to be larger (in relative terms) at the extreme bands of the spectrum, i.e. at 412 and $670 \mathrm{~nm}$, in the first case because of the spectral distance from the NIR bands used for the atmospheric correction and in the second because of the generally very low Rrs values that pose a challenge for both the in situ and satellite determination of the Rrs at this band. 


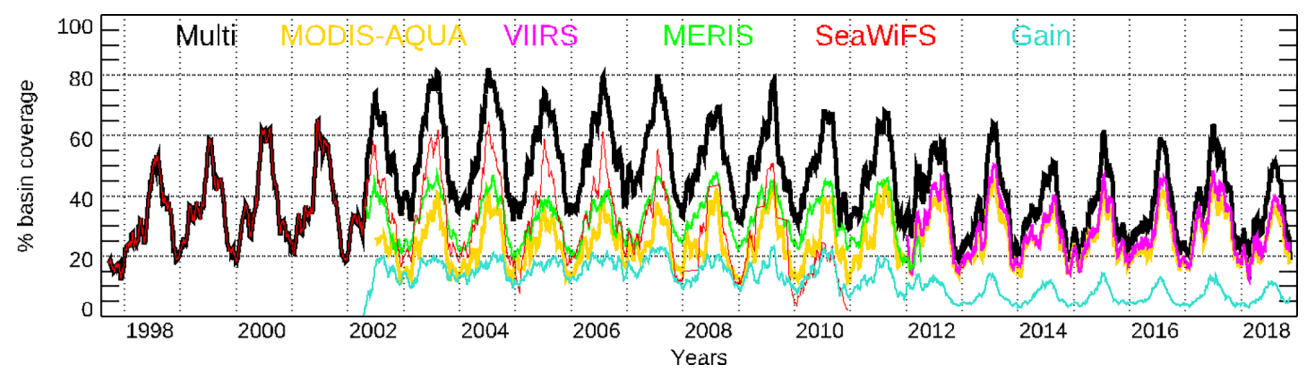

Figure 8. Time series of the number of pixels for each satellite sensor as a percent with respect to the basin total coverage. For the sake of readability, each line represents the result of the 30-day running median time series. The turquoise line is the basin coverage increase that is gained with the Multi product with respect to the maximum coverage from the single sensors.

Here, the difference between satellite and in situ Rrs observations at these extreme bands is of the same order of magnitude as the blue-green part of the spectrum when observed in the open ocean (MedBiOp and BOUSSOLE) but not in the coastal domain (AAOT). CCIv3 and Multi-Rrs present a generally good agreement, with differences between these two products and the in situ data being smaller than $5 \%$; this low difference is likely due to the two source datasets derived from two different NASA reprocessings, R2014 and R2018, and partially to the use of POLYMER for the MODIS Aqua processing in the CCI chain. At $412 \mathrm{~nm}$, and to a lesser extent at $443 \mathrm{~nm}$, this difference is more pronounced (more than 5\%) because the impact of the R2018 is larger at these bands. An even more evident difference (larger than 10\%) is seen at $670 \mathrm{~nm}$; here, the impact of R2018 should be less important than in the blue bands. One important difference between the Multi product and CCIv3 is that the Multi product is not bias-corrected over SeaWiFS at this band (Sect. 2.2.2); since SeaWiFS performances at this band are not as good as at the other bands it is reasonable to assume that this might be the cause of the observed discrepancy, further supporting the choice of not using SeaWiFS to bias-correct the other sensors in this band. Another important feature in Fig. 9 is the general difference in satellite performance (both the Multi product and CCIv3) in coastal and open waters.

Table 4 shows the number of matchups for each band of the Multi product and CCIv3 in correspondence to the three in situ datasets. Two aspects emerge: one linked to the difference between the Multi product and CCIv3 and the other between the $670 \mathrm{~nm}$ band and the other bands. As mentioned earlier, it is reasonable to assume that the different source data (R2018.0 for the Multi product and R2014.0 for CCIv3) are responsible for the differences in spatial coverage and hence in the number of matchups. Moreover, it should be mentioned that MODIS Aqua used in the multi-processing chain derives from NASA R2018.0, while it derives from the POLYMER atmospheric correction scheme for CCIv3. As for the differences between the $670 \mathrm{~nm}$ band and the other bands, the very noisy spatial patterns present in the daily images of the Rrs at $670 \mathrm{~nm}$ very often result, at the scale of the

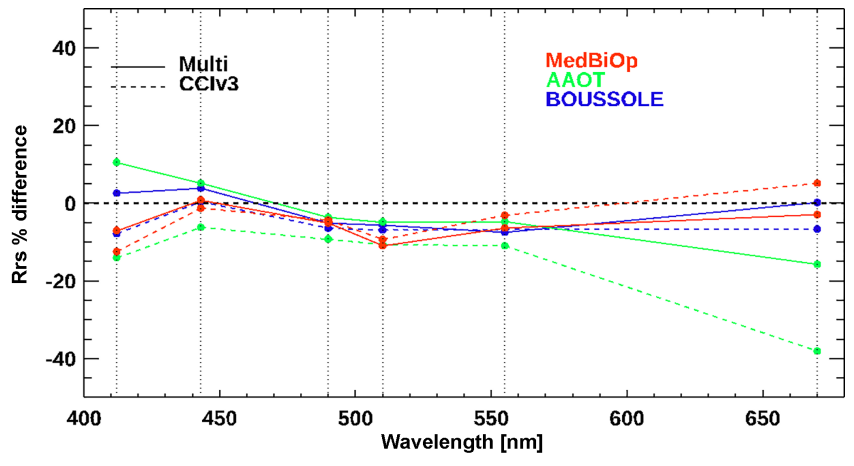

Figure 9. Relative difference between the Multi product and CCIv3 satellite observations and in situ measurements (MedBiOp in red, AAOT in green, and BOUSSOLE in blue). The number of matchups used from each dataset is summarized in Table 3. Target wavelengths are marked with vertical dotted lines. As a reference the two red lines correspond to the black and blue lines in Fig. 7 for the Multi product and CCIv3, respectively.

matchup pixels, in the coefficient of variation exceeding the $20 \%$ threshold (Sect. 2.3).

Overall, despite their absolute differences, the two multisensor satellite products show a similar level of accuracy, which suggests that the multi-processor is also suitable for the REP processing chain. This would provide the two benefits of reducing the number of upstream data providers and giving the NRT-DT and REP products full compatibility.

\subsection{Matchup - Chl}

Figure 10 shows the matchups for the $\mathrm{L} 3 \mathrm{Chl}$ product for both processing modes, REP (derived from the CCIv3 Rrs) and NRT-DT (derived from the multi-chain described in this study). To facilitate the comparison between the two satellite products, the matchup dataset includes only the points for which both satellite data are available. Both products are regularly distributed around the line of best agreement for the entire Chl range, although for in situ values larger than $0.3 \mathrm{mg} \mathrm{m}^{-3}$ there is a noticeable dispersion increase. Table 5 shows the statistics of the four datasets plotted in Fig. 10. To 
Table 4. Number of matchups used to compute the statistics presented in Fig. 9.

\begin{tabular}{llrrrrrr}
\hline \multirow{2}{*}{ In situ } & Satellite & \multicolumn{7}{c}{ Bands (nm) } \\
\cline { 3 - 8 } & & 412 & 443 & 490 & 510 & 555 & 670 \\
\hline \multirow{2}{*}{ MedBiOp } & Multi product & 272 & 272 & 272 & 272 & 272 & 197 \\
& CCIv3 & 262 & 262 & 262 & 262 & 262 & 223 \\
\hline \multirow{2}{*}{ AAOT } & Multi product & 1794 & 1794 & 1794 & 1794 & 1794 & 1301 \\
& CCIv3 & 1753 & 1753 & 1753 & 1753 & 1753 & 1504 \\
\hline \multirow{2}{*}{ BOUSSOLE } & Multi product & 961 & 961 & 961 & 961 & 961 & 780 \\
& CCIv3 & 882 & 882 & 882 & 882 & 882 & 780 \\
\hline
\end{tabular}

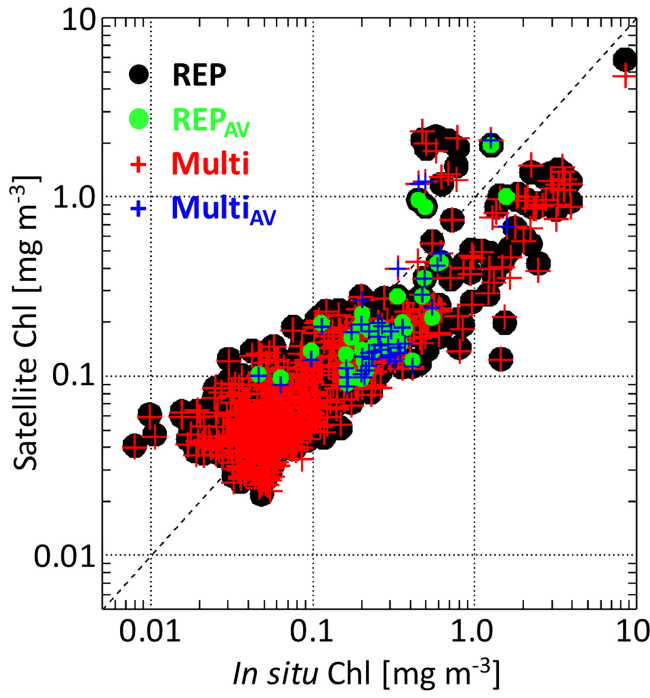

Figure 10. Satellite ( $y$ axis) versus in situ (MedBiOp) Chl concentration. Satellite $\mathrm{Chl}$ is the REP (derived by the application of the MedOC4.2018 to the Rrs derived from the CCIv3 processor, black) and NRT-DT (derived from the multi-processing, red). Green dots and blue crosses are the REP and NRT-DT for matchups on the period in which VIIRS and MODIS coexist $\left(\right.$ REP $_{\mathrm{AV}}$ and Multi $\left.\mathrm{AV}_{\mathrm{AV}}\right)$. Statistics associated with the matchup comparison are shown in Table 4 .

assess the uncertainties in the multi-Chl currently distributed on the CMEMS portal, the analysis was performed on the period in which VIIRS and MODIS coexist, i.e. January 2012 onwards. Despite the different number of matchups (44 vs. 710$)$ and different Chl ranges ( $\sim 0.04-2$ vs. $\sim 0.007-9)$, statistics associated with the full time series are totally comparable with those obtained with the most recent data only (2012 to present), as denoted by the AV (MODIS Aqua and VIIRS) subscript in both Fig. 10 and Table 5.

To further assess the level of accuracy associated with the Chl retrieval from the multi-mission merged approach presented in this study, we compared with the results at global scale reported in the Climate Assessment Report, CAR (CCI, 2017). Differently than here, in the CAR, the
Chl log-transformation was used to compute all the statistics, not only those associated with the linear fit (slope, intercept, and determination coefficient; Sect. 2.3). Therefore, for this analysis, we recomputed all the statistics in Table 5 accordingly (Table S10). The in situ data used to compute the CAR statistics are much more numerous (14 582; Table S10). Nonetheless, results for the proposed regional algorithms as well as for CCI at global and Mediterranean scales show a generally good agreement in terms of the determination coefficient, RMSD, CRMSD, and the slope of the linear fit. The difference in the intercept only reflects the difference in the two dataset ranges of variability, with the global set being wider and characterized by a larger modal value (centred over $\sim 1 \mathrm{mg} \mathrm{m}^{-3}$; Fig. 8 in CAR) than the MedBiOp (Fig. 10).

\subsection{Matchup - Kd490}

Figure 11a shows the validation result of the satellite-derived Kd490 with respect to the in situ Kd490 obtained from the BGC-Argo float dataset (Organelli et al., 2016), whose space-time distribution is shown in Fig. 11c. As a matter of comparison, both algorithms shown in Sect. 2.2.3 and in Fig. $6 \mathrm{~b}$ are presented. MedKd performs better than the global algorithm as also highlighted by their matchup statistics (Table S9), from which it appears that the regional algorithm presents lower biases (both absolute and percent) than the global. Similarly to the global, the MedKd algorithm overestimates in situ values larger than $0.1 \mathrm{~m}^{-1}$, probably due to the lower representativeness of the MedBiOp dataset used to derive the algorithm in this range of variability (Figs. $6 \mathrm{~b}$ and 11b). Furthermore, the global algorithm shows a clear overestimation at the lower end of the range of variability with respect to the in situ data, as well as to the regional algorithm, as shown by the two lines of best fit (slopes are 0.86 and 1 for the global and the MedKd, respectively; Table S9). In contrast, the MedKd algorithm performs well at low values.

A similar analysis from Organelli et al. (2017) shows that satellite data overestimate the BGC-Argo-derived Kd490 for values below $0.1 \mathrm{~m}^{-1}$ (their Fig. 11). Here, we show that this still holds when the global algorithm is used, but that 
Table 5. Statistics about the $\mathrm{Chl}\left(\mathrm{mg} \mathrm{m}^{-3}\right)$ matchup datasets described in Fig. 10. The first two rows refer to the comparison of the two satellite multi-sensor products with the entire MedBiOp Chl dataset, while the last two refer to the statistics associated with matchups on the period in which VIIRS and MODIS coexist $\left(\mathrm{REP}_{\mathrm{AV}}\right.$ and Multi $\left.\mathrm{AV}\right)$. A more comprehensive table of metrics is provided in the Supplement (Table S8).

\begin{tabular}{lcccccccr}
\hline Product & Slope & Intercept & $r^{2}$ & RMSD & Bias & RPD & APD & $N$ \\
\hline REP & 0.737 & -0.306 & 0.75 & 0.411 & -0.093 & 7 & 47 & 710 \\
Multi product & 0.752 & -0.309 & 0.74 & 0.427 & -0.098 & 3 & 47 & 710 \\
REP $_{\text {AV }}$ & 1.052 & -0.108 & 0.57 & 0.207 & -0.064 & -18 & 43 & 44 \\
Multi $_{\text {AV }}$ & 1.184 & -0.047 & 0.50 & 0.271 & -0.057 & -17 & 48 & 44 \\
\hline
\end{tabular}
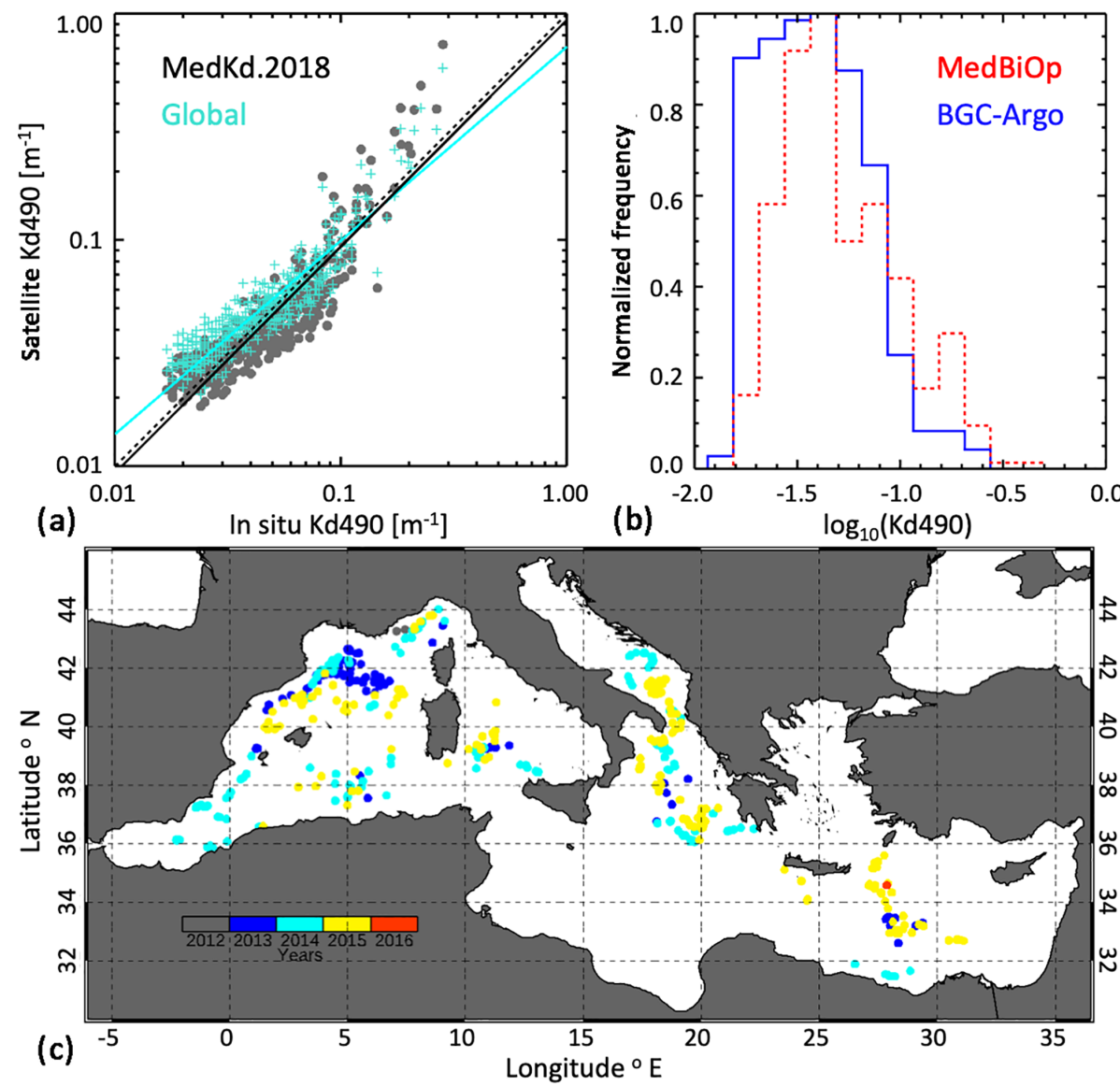

Figure 11. Satellite Kd validation with the BGC-Argo float dataset (Organelli et al., 2016). Panel (a) shows the in situ Kd ( $x$ axis) versus the satellite-derived Kd obtained with the MedKd.2018 (grey dots) and the global algorithm (turquoise dots), respectively, as shown in Fig. $6 \mathrm{~b}$. The two best-fit lines are also superimposed. The normalized frequency distribution of the two in situ Kd490 measurements (MedBiOp in red and the BGC-Argo in blue) is shown in panel (b). The space-time distribution of the matchups is shown in panel (c). Relevant statistics are available in the Supplement (Table S9).

the MedKd algorithm corrects for this overestimation. This analysis, performed over a fully independent dataset, justifies and supports the choice of using the MedKd algorithm for the operational chain in lieu of the global.

\section{Conclusions}

This work presented the latest achievements in the operational processing chain for the ocean colour data stream for the Mediterranean Sea in the context of the European Copernicus Marine Environment Monitoring Service. The development of the multi-sensor merged product builds on the previous version of this chain, which was focused on the par- 
allel processing of single sensors (SeaWiFS, MODIS, and MERIS; Volpe et al., 2012). The introduction of an operational multi-sensor merged product aims to meet the operational oceanography intrinsic requirement of "one question, one answer". Three main steps were implemented: band shifting, inter-sensor bias correction, and sensor merging. The band shifting is implemented exactly as in Mélin and Sclep (2015), while the implementation of the inter-sensor bias correction differs from the OC-CCI technique (CCI, 2016b) in the temporal and spatial aggregation scales. The sensor merging shown in this work is based on the use of the climatology as input to the smoothing procedure as described in Volpe et al. (2018). The output of this processing chain is the Rrs spectrum that constitutes the input to all algorithms used to derive the various geophysical products. The Rrs computed with the multi-sensor merging approach shows good agreement when compared with in situ observations not only with the basin-scale MedBiOp dataset but also with the two fixed-location AAOT and BOUSSOLE time series. As the accuracy of the L3 DT data presented in this study also depends on the sensor calibration of the L2 data used in the NRT-DT processing chain, the L3 operational products might become degraded for newer data if the calibration of the sensors starts diverging from the R2018 parameters. Moreover, this work presents an updated version of the empirical algorithms for $\mathrm{Chl}$ and $\mathrm{Kd}$ retrievals for the Mediterranean Sea based on the extended MedBiOp dataset. The comparison with the in situ observations yields good results when applied to both the Rrs derived from the CCIv3 processor and those derived from the multi-sensor merged processing shown here. This suggests the opportunity to use the proposed multi-sensor processing chain in the REP context as well.

Data availability. Data are available on the CMEMS web portal at http://marine.copernicus.eu/ (last access: 7 February 2019).

Supplement. The supplement related to this article is available online at: https://doi.org/10.5194/os-15-127-2019-supplement.

Author contributions. GV, SC, and VF contributed to the design and the implementation of the processing chain. GV, SC, VEB, and MB drafted the paper and performed the analysis. SC developed the SERDA software. VF and FLP processed the satellite data archive. ADC and MS contributed to the in situ data collection. ADC and FA processed the in situ pigment data. All authors supervised the work, providing continuous suggestions and feedback.

Competing interests. The authors declare that they have no conflict of interest.
Special issue statement. This article is part of the special issue "The Copernicus Marine Environment Monitoring Service (CMEMS): scientific advances". It is not associated with a conference.

Acknowledgements. We wish to thank the anonymous reviewers for detailed and pertinent comments that helped to greatly improve the paper. Giuseppe Zibordi, as PI of the AERONET-OC site of Venice, is warmly thanked for the Level 2 surface reflectance data processing and site maintenance. The authors are also grateful to the BOUSSOLE project for maintaining and providing high-quality surface reflectance data used for the validation of the satellite observations. The International Argo Project (a pilot programme of the Global Ocean Observing System) and the national programmes that contribute to it (http://www.argo.ucsd.edu, last access: 7 February 2019; http://argo.jcommops.org, last access: 7 February 2019) are very gratefully acknowledged. The NASA Ocean Biology Processing Group is acknowledged for providing Level 2 data used as input to the processing chain. This work has been performed in the context of the Ocean Colour Thematic Assembly Centre of the Copernicus Marine Environment and Monitoring Service (grant number: 77-CMEMS-TAC-OC).

Edited by: Pierre-Yves Le Traon

Reviewed by: two anonymous referees

\section{References}

Antoine, D., Guevel, P., Desté, J. F., Bécu, G., Louis, F., Scott, A. J., and Bardey, P.: The "BOUSSOLE" Buoy - A new transparentto-swell taut mooring dedicated to marine optics: Design, tests, and performance at sea, J. Atmos. Ocean. Tech., 25, 968-989, https://doi.org/10.1175/2007JTECHO563.1, 2008.

Bailey, S. W. and Werdell, P. J.: A multi-sensor approach for the on-orbit validation of ocean color satellite data products, Remote Sens. Environ., 102, 12-23, https://doi.org/10.1016/j.rse.2006.01.015, 2006.

Barnes, B. B., Cannizzaro, J. P., English, D. C., and Hu, C.: Validation of VIIRS and MODIS reflectance data in coastal and oceanic waters: An assessment of methods, Remote Sens. Environ., 220, 110-123, https://doi.org/10.1016/j.rse.2018.10.034, 2019.

Berthon, J. F., Zibordi, G., Doyle, J. P., Grossi, S., der Linde, D., and Targa, C.: Coastal atmosphere and sea time series (CoASTS), Part 2: Data Analysis, NASA Tech. Memo, 206892, vol. 20, edited by: Hooker, S. B. and Firestone, E. R., NASA Goddard Space Flight Center, Greenbelt, Maryland, 25 pp., 2002.

Bouali, M. and Ignatov, A.: Adaptive reduction of striping for improved sea surface temperature imagery from Suomi National Polar-Orbiting Partnership (S-NPP) Visible Infrared Imaging Radiometer Suite (VIIRS), J. Atmos. Ocean. Techn., 31, 150-163, https://doi.org/10.1175/JTECH-D-13-00035.1, 2014.

Bricaud, A., Bosc, E., and Antoine, D.: Algal biomass and sea surface temperature in the Mediterranean Basin Intercomparison of data from various satellite sensors, and implications for primary production estimates, Remote Sens. Environ., 81, 163-178, https://doi.org/10.1016/S0034-4257(01)00335-2, 2002. 
Brown, C. A., Huot, Y., Werdell, P. J., Gentili, B., and Claustre, H.: The origin and global distribution of second order variability in satellite ocean color and its potential applications to algorithm development, Remote Sens. Environ., 112, 4186-4203, https://doi.org/10.1016/j.rse.2008.06.008, 2008.

CCI: Ocean Colour Climate Change Initiative Product User Guide version 3.1, 47 pp., available at: http://www.esa-oceancolour-cci. org/ (last access: 7 February 2019), 2016a.

CCI: Ocean colour data bias correction and merging. Ocean colourClimate Change Initiative, algorithm theoretical basis document, version 3.7, 36 pp., available at: http://www.esa-oceancolour-cci. org/ (last access: 7 February 2019), 2016 b.

CCI: Ocean Colour Climate Change Initiative (Phase Two), Climate Assessment Report, AO-1/6207/09/I-LG, 125 pp., available at: http://esa-oceancolour-cci.org/?q=webfm_send/702 (last access: 7 February 2019), 2017.

Colella, S., Falcini, F., Rinaldi, E., Sammartino, M., and Santoleri, R.: Mediterranean ocean colour chlorophyll trends, PLoS One, 11, 1-16, https://doi.org/10.1371/journal.pone.0155756, 2016.

D'Alimonte, D. and Zibordi, G.: Phytoplankton determination in an optically complex coastal region using a multilayer perceptron neural network, IEEE T. Geosci. Remote, 41, 2861-2868, https://doi.org/10.1109/TGRS.2003.817682, 2003.

D'Alimonte, D., Mélin, F., Zibordi, G., and Berthon, J. F.: Use of the novelty detection technique to identify the range of applicability of empirical ocean color algorithms, IEEE T. Geosci. Remote, 41, 2833-2843, https://doi.org/10.1109/TGRS.2003.818020, 2003.

D’Alimonte, D., Zibordi, G., Kajiyama, T., and Cunha, J. C.: Monte Carlo code for high spatial resolution ocean color simulations, Appl. Optics, 49, 4936, https://doi.org/10.1364/AO.49.004936, 2010.

Dierssen, H. M.: Perspectives on empirical approaches for ocean color remote sensing of chlorophyll in a changing climate, P. Natl. Acad. Sci. USA, 107, 17073-17078, https://doi.org/10.1073/pnas.0913800107, 2010.

D’Ortenzio, F., Marullo, S., Ragni, M., D’Alcalà, M. R., and Santoleri, R.: Validation of empirical SeaWiFS algorithms for chlorophyll-a retrieval in the Mediterranean Sea: A case study for oligotrophic seas, Remote Sens. Environ., 82, 79-94, https://doi.org/10.1016/S0034-4257(02)00026-3, 2002.

Laws, E. A. and Archie, J. W.: Appropriate use of regression analysis in Marine Biology, Mar. Biol., 65, 13-16, 1981.

Lee, Z., Carder, K. L., and Arnone, R. A.: Deriving inherent optical properties from water color: a multiband quasi-analytical algorithm for optically deep waters, Appl. Optics, 41, 5755-5772, 2002.

Le Traon, P.-Y., Antoine, D., Bentamy, A., Bonekamp, H., Breivik, L. A., Chapron, B., Corlett, G., Dibarboure, G., DiGiacomo, P., Donlon, C., Faugère, Y., Font, J., Girard-Ardhuin, F., Gohin, F., Johannessen, J. A., Kamachi, M., Lagerloef, G., Lambin, J., Larnicol, G., Le Borgne, P., Leuliette, E., Lindstrom, E., Martin, M. J., Maturi, E., Miller, L., Mingsen, L., Morrow, R., Reul, N., Rio, M. H., Roquet, H., Santoleri, R., and Wilkin, J.: Use of satellite observations for operational oceanography: recent achievements and future prospects, J. Oper. Oceanogr., 8, s12s27, https://doi.org/10.1080/1755876X.2015.1022050, 2015.

Loew, A., Bell, W., Brocca, L., Bulgin, C. E., Burdanowitz, J., Calbet, X., Donner, R. V., Ghent, D., Gruber, A., Kaminski,
T., Kinzel, J., Klepp, C., Lambert, J. C., Schaepman-Strub, G., Schröder, M., and Verhoelst, T.: Validation practices for satellite-based Earth observation data across communities, Rev. Geophys., 55, 779-817, https://doi.org/10.1002/2017RG000562, 2017.

Manzella, G. M. R., Hopkins, T. S., Minnett, P. J., and Nacini, E.: Atlantic water in the Strait of Sicily, J. Geophys. Res., 95, 15691575, 1990.

Maritorena, S. and Siegel, D. A.: Consistent merging of satellite ocean color data sets using a biooptical model, Remote Sens. Environ., 94, 429-440, https://doi.org/10.1016/j.rse.2004.08.014, 2005.

Mélin, F. and Sclep, G.: Band shifting for ocean color multi-spectral reflectance data, Opt. Express, 23, 2262, https://doi.org/10.1364/OE.23.002262, 2015.

Mélin, F., Vantrepotte, V., Clerici, M., D’Alimonte, D., Zibordi, G., Berthon, J. F., and Canuti, E.: Multi-sensor satellite time series of optical properties and chlorophyll-a concentration in the Adriatic Sea, Prog. Oceanogr., 91, 229-244, https://doi.org/10.1016/j.pocean.2010.12.001, 2011.

Mikelsons, K., Wang, M., Jiang, L., and Bouali, M.: Destriping algorithm for improved satellite-derived ocean color product imagery, Opt. Express, 22, 28058, https://doi.org/10.1364/OE.22.028058, 2014.

Mobley, C. D., Werdell, J., Franz, B., Ahmad, Z., and Bailey, S.: Atmospheric Correction for Satellite Ocean Color Radiometry, NASA Tech. Memo., (NASA/TM-2016-217551), 73 pp., 2016.

Moore, T. S., Dowell, M. D., Bradt, S., and Ruiz Verdu, A.: An optical water type framework for selecting and blending retrievals from bio-optical algorithms in lakes and coastal waters, Remote Sens. Environ., 143, 97-111, https://doi.org/10.1016/j.rse.2013.11.021, 2014.

Morel, A. and Prieur, L.: Analysis of variations in ocean color, Limnol. Oceanogr., 22, 709-722, https://doi.org/10.4319/lo.1977.22.4.0709, 1977.

Mueller, J. L.: SeaWiFS Algorithm for the Diffuse Attenuation Coefficient, K(490), Using Water-Leaving Radiances at 490 and $555 \mathrm{~nm}$, in: SeaWiFS postlaunch calibration Valid. Anal. Part 3, edited by: Hooker, S. B. and Firestone, E. R., Goddard Space Flight Center, Greenbelt, NASA Tech. Memo. 2000-206892, vol. 11, 24-27, 2000.

Mueller, J. L. and Austin, R. W.: Ocean Optics Protocols for SeaWiFS Validation, Revision 1, in: SeaWiFS Technical Report Series, NASA Technical Memorandum 104566, Vol. 25, edited by: Hooker, S. B., Firestone, E. R., and Acker, J. G., Goddard Space Flight Center, Greenbelt, 1995.

O’Reilly, J. E., Maritorena, S., Siegel, D. A., O’Brien, M. C., Toole, D., Mitchell, B. G., Kahru, M., Chaves, F. P., Strutton, P., Cota, G. F., Hooker, S. B., McClain, C. R., Carder, K. L., Muller-Karger, F., Harding, L., Magnuson, A., Phinney, D., Moore, G. F., Aiken, J., Arrigo, K. R., Letelier, R., and Culver, M.: Ocean Color Chlorophyll a Algorithms for SeaWiFS, OC2, and OC4: Version 4, in: SeaWiFS Postlaunch Tech. Rep. Ser. vol. 11, SeaWiFS postlaunch calibration Valid. Anal. Part 3, edited by: Hooker, S. B. and Firestone, E. R., Goddard Space Flight Center, Greenbelt, 9-23, https://doi.org/10.1103/PhysRevLett.104.255302, 2000.

Organelli, E., Barbieux, M., Claustre, H., Schmechtig, C., Poteau, A., Bricaud, A., Uitz, J., D’Ortenzio, F., and Dall'Olmo, 
G.: A global biooptical database derived from Biogeochemical Argo float measurements within the layer of interest for field and remote ocean color applications, SEANOE, https://doi.org/10.17882/47142, 2016.

Organelli, E., Barbieux, M., Claustre, H., Schmechtig, C., Poteau, A., Bricaud, A., Boss, E., Briggs, N., Dall'Olmo, G., D’Ortenzio, F., Leymarie, E., Mangin, A., Obolensky, G., Penkerc'h, C., Prieur, L., Roesler, C., Serra, R., Uitz, J., and Xing, X.: Two databases derived from BGC-Argo float measurements for marine biogeochemical and bio-optical applications, Earth Syst. Sci. Data, 9, 861-880,https://doi.org/10.5194/essd-9-861-2017, 2017.

Pitarch, J., Bellacicco, M., Volpe, G., Colella, S., and Santoleri, R.: Use of the quasi-analytical algorithm to retrieve backscattering from in-situ data in the Mediterranean Sea, Remote Sens. Lett., 7, 591-600, https://doi.org/10.1080/2150704X.2016.1171922, 2016.

Santoleri, R., Volpe, G., Marullo, S., and Nardelli, B. B.: Open waters optical remote sensing of the Mediterranean Sea, in: Remote Sensing of the European Seas, edited by: Barale, V. and Gade, M., Springer, Dordrecht, 103-116, https://doi.org/10.1007/9781-4020-6772-3_8, 2008.

Sathyendranath, S. User requirements document, Technical Report ESA/ESRIN, available at: http://www.esa-oceancolour-cci.org/ (last access: 7 February 2019), 2011.

Sathyendranath, S., Brewin, R. J. W., Jackson, T., Mélin, F., and Platt, T.: Ocean-colour products for climate-change studies: What are their ideal characteristics?, Remote Sens. Environ., 203, 125-138, https://doi.org/10.1016/j.rse.2017.04.017, 2017.

Steinmetz, F., Deschamps, P.-Y., and Ramon, D.: Atmospheric correction in presence of sun glint: application to MERIS, Opt. Express, 19, 9783, https://doi.org/10.1364/OE.19.009783, 2011.

Szeto, M., Werdell, P. J., Moore, T. S., and Campbell, J. W.: Are the world's oceans optically different?, J. Geophys. Res., 116, C00H04, https://doi.org/10.1029/2011JC007230, 2011.

Teruzzi, A., Dobricic, S., Solidoro, C., and Cossarini, G.: A 3-D variational assimilation scheme in coupled transportbiogeochemical models: Forecast of Mediterranean biogeochemical properties, J. Geophys. Res.-Oceans, 119, 200-217, https://doi.org/10.1002/2013JC009277, 2014.

Thuillier, G., Labs, D., Foujols, T., Peetermans, W., Gillotay, D., Simon, P. C., and Mandel, H.: The solar spectral irradiance from 200 to $2400 \mathrm{~nm}$ as measured by the SOLSPEC spectrometer from the ATLAS and EURECA missions, Sol. Phys., 214, 1-22, https://doi.org/10.1023/A:1024048429145, 2003.

Valente, A., Sathyendranath, S., Brotas, V., Groom, S., Grant, M., Taberner, M., Antoine, D., Arnone, R., Balch, W. M., Barker, K., Barlow, R., Bélanger, S., Berthon, J.-F., Besiktepe, S., Brando, V., Canuti, E., Chavez, F., Claustre, H., Crout, R., Frouin, R., García-Soto, C., Gibb, S. W., Gould, R., Hooker, S., Kahru, M., Klein, H., Kratzer, S., Loisel, H., McKee, D., Mitchell, B. G., Moisan, T., Muller-Karger, F., O’Dowd, L., Ondrusek, M., Poulton, A. J., Repecaud, M., Smyth, T., Sosik, H. M., Twardowski, M., Voss, K., Werdell, J., Wernand, M., and Zibordi, G.: A compilation of global bio-optical in situ data for oceancolour satellite applications, Earth Syst. Sci. Data, 8, 235-252, https://doi.org/10.5194/essd-8-235-2016, 2016.

Volpe, G., Santoleri, R., Vellucci, V., Ribera d'Alcalà, M., Marullo, S., and D'Ortenzio, F.: The colour of the Mediterranean Sea:
Global versus regional bio-optical algorithms evaluation and implication for satellite chlorophyll estimates, Remote Sens. Environ., 107, 625-638, https://doi.org/10.1016/j.rse.2006.10.017, 2007.

Volpe, G., Colella, S., Forneris, V., Tronconi, C., and Santoleri, R.: The Mediterranean Ocean Colour Observing System - system development and product validation, Ocean Sci., 8, 869-883, https://doi.org/10.5194/os-8-869-2012, 2012.

Volpe, G., Buongiorno Nardelli, B., Colella, S., Pisano, A., and Santoleri, R.: An Operational Interpolated Ocean Colour Product in the Mediterranean Sea, in: New Frontiers in Operational Oceanography, edited by: Chassignet, E. P., Pascual, A., Tintorè, J., and Verron, J., GODAE OceanView, 227-244, 2018.

von Schuckmann, K., Le Traon, P. Y., Alvarez-Fanjul, E., Axell, L., Balmaseda, M., Breivik, L. A., Brewin, R. J. W., Bricaud, C., Drevillon, M., Drillet, Y., Dubois, C., Embury, O., Etienne, H., Sotillo, M. G., Garric, G., Gasparin, F., Gutknecht, E., Guinehut, S., Hernandez, F., Juza, M., Karlson, B., Korres, G., Legeais, J. F., Levier, B., Lien, V. S., Morrow, R., Notarstefano, G., Parent, L., Pascual, Á., Pérez-Gómez, B., Perruche, C., Pinardi, N., Pisano, A., Poulain, P. M., Pujol, I. M., Raj, R. P., Raudsepp, U., Roquet, H., Samuelsen, A., Sathyendranath, S., She, J., Simoncelli, S., Solidoro, C., Tinker, J., Tintoré, J., Viktorsson, L., Ablain, M., Almroth-Rosell, E., Bonaduce, A., Clementi, E., Cossarini, G., Dagneaux, Q., Desportes, C., Dye, S., Fratianni, C., Good, S., Greiner, E., Gourrion, J., Hamon, M., Holt, J., Hyder, P., Kennedy, J., Manzano-Muñoz, F., Melet, A., Meyssignac, B., Mulet, S., Buongiorno Nardelli, B., O’Dea, E., Olason, E., Paulmier, A., Pérez-González, I., Reid, R., Racault, M. F., Raitsos, D. E., Ramos, A., Sykes, P., Szekely, T., and Verbrugge, N.: The Copernicus Marine Environment Monitoring Service Ocean State Report, J. Oper. Oceanogr., 9, s235-s320, https://doi.org/10.1080/1755876X.2016.1273446, 2016.

von Schuckmann, K., Le Traon, P.-Y., Smith, N., Pascual, A., Brasseur, P., Fennel, K., Djavidnia, S.,, Aaboe, S., Alvarez Fanjul, E., Autret, E., Axell, L., Aznar, R., Benincasa, M., Bentamy, A., Boberg, F., Bourdallé-Badie, R., Buongiorno Nardelli, B., Brando, V. E., Bricaud, C., Breivik, L.-A., Brewin, R. J. W., Capet, A., Ceschin, A., Ciliberti, S., Cossarini, G., de Alfonso, M., de Pascual Collar, A., de Kloe, J., Deshayes, J., Desportes, C., Drévillon, M., Drillet, Y., Droghei, R., Dubois, C., Embury, O., Etienne, H., Fratianni, C., García Lafuente, J., Garcia Sotillo, M., Garric, G., Gasparin, F., Gerin, R., Good, S., Gourrion, J., Grégoire, M., Greiner, E., Guinehut, S., Gutknecht, E., Hernandez, F., Hernandez, O., Høyer, J., Jackson, L., Jandt, S., Josey, S., Juza, M., Kennedy, J., Kokkini, Z., Korres, G., Kõuts, M., Lagemaa, P., Lavergne, T., le Cann, B., Legeais, J.-F., Lemieux-Dudon, B., Levier, B., Lien, V., Maljutenko, I., Manzano, F., Marcos, M., Marinova, V., Masina, S., Mauri, E., Mayer, M., Melet, A., Mélin, F., Meyssignac, B., Monier, M., Müller, M., Mulet, S., Naranjo, C., Notarstefano, G., Paulmier, A., Pérez Gomez, B., Pérez Gonzalez, I., Peneva, E., Perruche, C., Peterson, K. A., Pinardi, N., Pisano, A., Pardo, S., Poulain, P.-M., Raj, R. P., Raudsepp, U., Ravdas, M., Reid, R., Rio, M.-H., Salon, S., Samuelsen, A., Sammartino, M., Sammartino, S., Sandø, A. B., Santoleri, R., Sathyendranath, S., She, J., Simoncelli, S., Solidoro, C., Stoffelen, A., Storto, A., Szerkely, T., Tamm, S., Tietsche, S., Tinker, J., Tintore, J., Trindade, A., van Zanten, D., Vandenbulcke, L., Verhoef, A., 
Verbrugge, N., Viktorsson, L., von Schuckmann, K., Wakelin, S. L., Zacharioudaki, A., and Zuo, H.: Copernicus Marine Service Ocean State Report, J. Operat. Oceanogr., 11, S1-S142, https://doi.org/10.1080/1755876X.2018.1489208, 2018.

Werdell, P. J. and Bailey, S. W.: An improved in-situ bio-optical data set for ocean color algorithm development and satellite data product validation, Remote Sens. Environ., 98, 122-140, https://doi.org/10.1016/j.rse.2005.07.001, 2005.

Zibordi, G. and Ferrari, G. M.: Instrument self-shading in underwater optical measurements: experimental data, Appl. Optics, 34, 2750-2754, https://doi.org/10.1364/AO.34.002750, 1995.

Zibordi, G., Hooker, S. B., Berthon, J. F., and D'Alimonte, D.: Autonomous above-water radiance measurements from an offshore platform: A field assessment experiments, J. Atmos. Ocean. Tech., 19, 808-819, https://doi.org/10.1175/15200426(2002)019<0808:AAWRMF>2.0.CO;2, 2002.

Zibordi, G., D'Alimonte, D., and Berthon, J. F.: An evaluation of depth resolution requirements for optical profiling in coastal waters, J. Atmos. Ocean. Tech., 21, 1059-1073, https://doi.org/10.1175/15200426(2004)021<1059:AEODRR>2.0.CO;2, 2004.
Zibordi, G., Holben, B., Slutsker, I., Giles, D., D'alimonte, D., Mélin, F., Berthon, J. F., Vandemark, D., Feng, H., Schuster, G., Fabbri, B. E., Kaitala, S., and Seppälä, J.: AERONET-OC: A network for the validation of ocean color primary products, J. Atmos. Ocean. Tech., 26, 1634-1651, https://doi.org/10.1175/2009JTECHO654.1, 2009.

Zibordi, G., Berthon, J. F., Mélin, F., and D'Alimonte, D.: Crosssite consistent in situ measurements for satellite ocean color applications: The BiOMaP radiometric dataset, Remote Sens. Environ., 115, 2104-2115, https://doi.org/10.1016/j.rse.2011.04.013, 2011.

Zibordi, G., Ruddick, K., Ansko, I., Moore, G., Kratzer, S., Icely, J., and Reinart, A.: In situ determination of the remote sensing reflectance: an inter-comparison, Ocean Sci., 8, 567-586, https://doi.org/10.5194/os-8-567-2012, 2012. 